This preprint is for a manuscript submitted for publication in Remote Sensing of Environment. Note that the content may change somewhat in subsequent versions of the manuscript. Please feel free to contact any of the authors if you have any feedback or suggestions. 


\title{
On the Land Emissivity Assumption and Landsat-Derived Surface Urban Heat Islands: A Global Analysis
}

\author{
TC Chakraborty ${ }^{1}$ \\ Yale School of the Environment \\ Xuhui Lee \\ Yale School of the Environment \\ Sofia Ermida \\ Instituto Portugues do Mar e da Atmosfera \\ Wenfeng Zhan \\ Nanjing University
}

\begin{abstract}
The prescription of surface emissivity $(\varepsilon)$ strongly controls satellite-derived estimates of land surface temperature (LST). This is particularly important for studying surface urban heat islands (SUHI) since built-up and natural landscapes are known to have distinct $\varepsilon$ values. Given the small signal associated with the SUHI compared to LST, accurately prescribing urban and rural $\varepsilon$ would improve our satellite-derived SUHI estimates. Here we test the sensitivity of SUHI to the $\varepsilon$ assumption made while deriving LST from Landsat measurements for almost 10,000 global urban clusters for summer and winter days. We find that adjusting the $\varepsilon$ values from the Advanced Spaceborne Thermal Emission and Reflection Radiometer (ASTER) dataset based on pixel-level normalized difference vegetation index (NDVI) increases the summer to winter contrast in daytime SUHI, which has been shown in previous studies. Overall, the difference between the two methods of prescribing $\varepsilon$, one from ASTER
\end{abstract}

\footnotetext{
${ }^{1}$ Corresponding Author: tc.chakraborty@yale.edu
} 
and one after NDVI-adjustment, is moderate; around 10\% during summer and around $20 \%$ during winter, though this difference varies by climate zone, showing higher deviations in polar and temperate climate. We also combine five different methods of prescribing emissivity to provide the first global estimates of SUHI derived from Landsat. The global ensemble mean SUHI varies between $2.42{ }^{\circ} \mathrm{C}$ during summer to $0.46{ }^{\circ} \mathrm{C}$ in winter. Regardless of the surface emissivity model used, compared to Moderate Resolution Imaging Spectroradiometer (MODIS) Terra observations, Landsat data show higher SUHI daytime intensities during summer (by more than $1.5^{\circ} \mathrm{C}$ ), partly due to its ability to better resolve urban pixels. We also find that the $\varepsilon$ values prescribed for urban land cover in global and regional weather models are lower than the satellite-derived broadband $\varepsilon$ values. Computing sensitivities of urban and rural LST to $\varepsilon$, we demonstrate that this would lead to overestimation of SUHI by these models (by around $4{ }^{\circ} \mathrm{C}$ for both summer and winter), all else remaining constant. Our analysis provides a global perspective on the importance of better constraining urban $\varepsilon$ for comparing satellite-derived and model-simulated SUHI intensities. Since both the structural and geometric heterogeneity of the surface controls the bulk $\varepsilon$, future studies should try to benchmark the suitability of existing LST- $\varepsilon$ separation methods over urban areas.

Keywords: Land Surface Temperature, Urban Heat Island, Surface emissivity, Landsat, MODIS, Global, Google Earth Engine

\section{Introduction}

The physical process of urbanization involves replacement of natural landscapes with built-up structures, modifying the biophysical properties of the land surface (Carlson and Arthur, 2000). One major and widely studied consequence of urbanization is the urban heat island (UHI) effect. The UHI is the usually positive temperature difference between an urban area and its non-urban reference, essentially isolating the impact of urbanization on local temperature Oke, 1969, 1982 Arnfield, 2003). The UHI can contribute to urban heat stress, en- 
hance energy demand for cooling, and may impact local-scale cloud cover and rainfall (Arnfield, 2003 Shastri et al., 2015, Li et al., 2019, Theeuwes et al. 2019).

Traditionally, the UHI has been quantified as the difference in near-surface air temperature (AT) between the urban core and a rural reference (Voogt, 2007). Since urban areas can have large heterogeneity, it can be difficult to capture a representative value of urban temperature using standard weather stations (Stewart, 2011). Moreover, dense meteorological networks, which are rarely available over cities (Muller et al., 2013), are necessary to capture the intra-urban temperature variability, which has implications for disparities in heat exposure (Chakraborty et al., 2019a, Hoffman et al., 2020, Chakraborty et al., 2020, Hsu et al., 2021). The advent of satellite observations in the thermal infrared (TIR) channels has allowed researchers to remotely measure the land surface temperature (LST) over urban areas (Rao, 1972). Although LST and AT are not physically identical quantities, it is easier to estimate intraurban variability in LST from satellites due to their spatially explicit coverage. The global availability of some of these LST products has also enabled multicity comparisons that are difficult using ground-based observations (Peng et al. 2011, Clinton and Gong, 2013, Chakraborty and Lee, 2019). The UHI derived using satellite data is commonly referred to as surface UHI (SUHI), while traditional weather station-based UHI estimates are known as canopy UHI (CUHI) (Bonafoni et al., 2015, Chakraborty et al., 2016, Venter et al., 2021).

Although satellite-based LST has several advantages over ground-based observations of AT, its accuracy depends on several factors (Dash et al., 2002). Satellites measure the top of the atmosphere thermal radiance $\left(L_{\lambda, \text { toa }}\right)$, which can be approximated as:

$$
L_{\lambda, \mathrm{toa}}=\tau \varepsilon B_{\lambda}(\mathrm{LST})+L_{\lambda, \mathrm{u}, \mathrm{atm}}+L_{\lambda, \mathrm{d}, \mathrm{atm}}(1-\varepsilon) \tau
$$

Here $\varepsilon$ is the surface emissivity, $\tau$ is the atmospheric transmissivity, $B_{\lambda}$ is the black body radiance corresponding to the LST, and $L_{\lambda, \mathrm{u}, \text { atm }}$ and $L_{\lambda, \mathrm{d} \text {,atm }}$ are 
the upward and downward components of the thermal radiance from the bulk atmosphere. All of these variables are wavelength dependent and the radiance components have the unit of $\mathrm{W} \mathrm{m} \mathrm{m}^{-2} \mu \mathrm{m}^{-1} \mathrm{sr}^{-1}$. The measured $L_{\lambda, \text { toa }}$ is then combined with multiple ancillary data to estimate $B_{\lambda}$. Finally, the LST is computed from $B_{\lambda}$ by inverting Planck's law. The values of $\tau, L_{\lambda, \mathrm{u} \text {,atm }}$, and $L_{\lambda, \mathrm{d} \text {,atm }}$ are dependent on atmospheric conditions and may be obtained from radiative transfer models. On the other hand, $\varepsilon$ - a spectrally varying ratio of emitted radiation of a material compared to the radiation of a black body at a particular temperature - is primarily a property of the land surface (Li et al. $2013 \mathrm{~b}$.

Since both $\varepsilon$ and LST determine the total thermal radiation captured by satellites, estimates of $\varepsilon$ are a pre-requisite for accurately calculating LST. Unfortunately, even if the atmospheric properties that influence $\tau, L_{\lambda, \mathrm{u} \text {,atm }}$, and $L_{\lambda, \mathrm{d} \text {,atm }}$ are perfectly known, $\varepsilon$ and LST cannot be analytically separated from satellite observations (Hook et al., 1992, Dash et al., 2002, Li et al., 2013a). Conceptually, for TIR measurements in $n$ channels, we get $n$ equations (one for each channel) for $n+1$ unknowns ( $\varepsilon$ for $n$ channels and LST). As such, several empirical methods are used to determine $\varepsilon$. The first is a temperature emissivity separation (TES) method that solves the $n$ equations with an additional empirical constraint to equalize the number of equations and unknowns Gillespie et al. 1998). Another is an NDVI-based emissivity method (NBEM), where the emissivity is expressed as a function of the normalized difference vegetation index (NDVI), a proxy for live green surface vegetation (Van de Griend and OWE, 1993, Valor and Caselles, 1996). Finally, there are classification-based emissivity methods (CBEM), with each land cover prescribed a value based on look-up tables (Snyder et al., 1998). Each method has its advantages and disadvantages (Dash et al. 2002) and the choice of method is of particular concern when studying the SUHI (Mohamed et al., 2017). Although the vast majority of studies that use the derived LST products from Moderate Resolution Imaging Spectroradiometer (MODIS) observations implicitly use a CBEM method, there is less agreement on the method used to estimate LST from Landsat observa- 
tions in the scientific literature (Sekertekin and Bonafoni, 2020a). Regardless

of the method used, specifications of $\varepsilon$ lead to some of the largest uncertainties in satellite-derived LST (Jiménez-Muñoz and Sobrino, 2003).

The challenge of accurately prescribing $\varepsilon$ is particularly difficult for urban areas (Artis and Carnahan, 1982; Mohamed et al. 2017). Real urban areas vary widely in material composition of the built-up structures, varying presence of other land cover types like vegetation, barren soil, and undeveloped land, as well as large differences in surface geometry that can also influence bulk $\varepsilon$ (Voogt and Oke, 1998, Mitraka et al., 2012; Quan et al., 2016). A single value for urban $\varepsilon$, which is frequently used in many CBEM methods, is simplistic since the different materials used in urban construction have widely different $\varepsilon$ (Marshall, 1982 Chen et al. 2016). Also, NBEM methods are affected by this uncertainty since NDVI-based threshold cannot explicitly account for differences in the built-up structures and surface geometry across cities (Dash et al., 2002). Even within cities, different materials, and thus different $\varepsilon$ values, are common, with potential impacts on estimating intra-urban LST variability from higher resolution satellite observations, such as from Landsat (Artis and Carnahan, 1982). TES methods, although conceptually the most accurate, are influenced by the relatively higher uncertainties in satellite observations over urban areas due to multiple factors, from urban heterogeneity to thermal anisotropy (Lagouarde et al. 2004; $\mathrm{Hu}$ et al. 2016). Moreover, this method requires observations in several TIR channels.

Although the SUHI is a derived quantity, expressed as the difference between urban and rural LSTs, it is one of the most studied metrics in urban climatology and is intended to isolate the impact of urbanization on local temperatures (Peng et al., 2011; Zhao et al., 2014, Clinton and Gong, 2013, Chakraborty and Lee, 2019. Manoli et al. 2020). Previous studies on the importance of $\varepsilon$ on urban LST have primarily focused on the overall $\varepsilon$ of individual cities (Chen et al. 2016, Mohamed et al. 2017), not the urban-rural differential in $\varepsilon(\Delta \varepsilon)$ and how that might impact the computed SUHI for global urban areas. The method of estimating $\Delta \varepsilon$ would affect the SUHI estimate even when the emitted thermal 
differential between urban and rural areas is held constant, since urban areas are known to have a distinct $\varepsilon$ from most natural surfaces (Sobrino et al. 2012 Yang et al. 2015). The $\Delta \varepsilon$ would also vary across different cities since both the typology of building materials (Voogt and Oke, 2003) and the land cover of the rural reference vary (Van de Griend and OWE, 1993, Zhao et al., 2014). The combined impact of these two sources of variability in $\varepsilon$ on SUHI estimates across cities has not been studied in the past. The influence of $\Delta \varepsilon$ on SUHI estimates is also important for regional and global land models. Land models have improved from using broadband $\varepsilon$ of 1 for all land surfaces in old global models (Sellers et al., 1986) to using land cover specific prescribed $\varepsilon$ in more recent implementations (Jin and Liang, 2006, Chakraborty et al., 2019b). The use of prescribed $\varepsilon$ is of particular concern for urban modeling studies due to the lack of observational constraints on this parameter as well as the large differences seen between prescribed and measured $\varepsilon$ (Li et al., 2017).

Here we attempt to comprehensively examine the impact of the $\varepsilon$ assumption on estimates of Landsat-derived SUHI both globally and across broad climate classes for the year 2010. Our goal is to add to the recent studies that have investigated the influence of the methods used while calculating the SUHI including choice of temporal composites and LST products ( $\mathrm{Hu}$ and Brunsell, 2013 Chakraborty et al. 2020, Yao et al. 2020), as well as definitions of the nonjurban reference (Chakraborty and Lee, 2019, Zhang et al., 2019, Chakraborty et al. 2020) - with a focus on the fundamental derivation of LST from satellite measures of thermal radiance. We also use this opportunity to provide the first global estimates of daytime SUHI using Landsat observations for several different methods of $\varepsilon$ prescription and discuss their potential applications and limitations when compared to more commonly used MODIS-derived values. Finally, to provide an integrated perspective on future research directions in urban climatology, we discuss the implications of the prescribed $\varepsilon$ in modeled SUHI estimates when compared to satellite-derived 'observations'. 


\section{Material and methods}

\subsection{Deriving land surface temperature}

Here we estimated global LST by combining top of the atmosphere brightness temperature $\left(T_{\mathrm{b}}\right)$ data and a vegetation index derived from the Landsat 5 satellite (Loveland and Dwyer, 2012) and $\varepsilon$ estimates from the Advanced Spaceborne Thermal Emission and Reflection Radiometer (ASTER) sensor (Abrams, 2000). The Landsat 5 satellite orbited the Earth in a sun-synchronous, nearpolar orbit and had a 16-day repeat cycle with an equatorial crossing time of around 9:45 am local time. The satellite observed the Earth in 7 channels, with all but the TIR channel (10.4 - $12.5 \mu \mathrm{m} ; 120 \mathrm{~m}$ native resolution) having a native resolution of $30 \mathrm{~m}$. Data from Landsat 5 are available from 1984 to 2012. ASTER is a multi-spectral imaging instrument on board the Terra satellite, which has a sun-synchronous orbit and crosses the equator at roughly 10:30 am local time. ASTER and its subsystems have been imaging the Earth's surface in 14 channels with a repeat cycle of 16 days since the year 2000. The resolution varies from $15 \mathrm{~m}$ for the VNIR (Visible and Near-Infrared) bands to $30 \mathrm{~m}$ for the SWIR (ShortWave Infrared) bands to $90 \mathrm{~m}$ for its 5 TIR channels $(8.125$ - $8.475 \mu \mathrm{m}, 8.475-8.825 \mu \mathrm{m}, 8.925-9.275 \mu \mathrm{m}, 10.25-10.95 \mu \mathrm{m}$, and 10.95-11.65 $\mu \mathrm{m})$.

Since $T_{\mathrm{b}}$ and LST are non-linearly related and all terms of Eq. 1 are not known for every pixel, generalized models used to estimate LST from satellite observations usually linearize the radiative transfer equation, which includes both a linearization of the Planck's function and contributions from atmospheric interference. Here we use the Statistical Mono-Window (SMW) algorithm as implemented by Ermida et al. (2020) on the Google Earth Engine (GEE) platform (Gorelick et al. 2017) to compute LST. The SMW algorithm represents LST as a linear function of prescribed $\varepsilon$ and the Landsat-observed $T_{\mathrm{b}}$ (Duguay-Tetzlaff et al. 2015) and is given by:

$$
\mathrm{LST}=A_{\mathrm{i}} \frac{T b}{\varepsilon}+B_{\mathrm{i}} \frac{1}{\varepsilon}+C_{\mathrm{i}}
$$


Here the coefficients of the equation for Landsat band $i\left(A_{\mathrm{i}}, B_{\mathrm{i}}\right.$, and $\left.C_{\mathrm{i}}\right)$ were derived from radiative transfer simulations for 10 classes of Total Column Water Vapour (TCWV). For more information about the calibration procedure used to estimate these coefficients, please see Ermida et al. (2020). The SMW algorithm has been found to perform well when validated against pyrgeometer observations at SURFRAD stations (Augustine et al., 2005). For the five SURFRAD stations considered in Sekertekin and Bonafoni (2020a), the SMW-derived LST from Landsat 5 has a root-mean-square error (RMSE) ranging from 1.7 to $2.6 \mathrm{~K}$ after removing outliers (Ermida et al., 2020). In comparison, the composite RMSE for the best performing algorithm using Landsat 5 data in Sekertekin and Bonafoni (2020a) was $2.35 \mathrm{~K}$.

\subsection{Surface emissivity for land surface temperature estimation}

Equation 2 is a function of prescribed $\varepsilon$, which is estimated using two methods in the GEE implementation of the SMW algorithm - the TES method used to generate the ASTER Global Emissivity Database version 3 (ASTER GEDv3) and a NBEM approach. The ASTER GEDv3 dataset was developed by the the National Aeronautics and Space Administration's (NASA) Jet Propulsion Labpratory (JPL) from clear-sky ASTER images between 2000 and 2008 (Hulley et al. 2015). The data are available at a resolution of $100 \mathrm{~m}$ for all 5 of ASTER's TIR channels. These data can be directly used in Eq. 2 after adjusting to the Landsat TIR band using the equation described in Malakar et al. (2018):

$$
\varepsilon_{10.40-12.5}=c_{13} \varepsilon_{13}+c_{14} \varepsilon_{14}+c
$$

Here $\varepsilon_{10.40-12.5}$ corresponds to the $\varepsilon$ for the Landsat 5 TIR channel, $\varepsilon_{13}$ and $\varepsilon_{14}$ correspond to band $13(10.25-10.95 \mu \mathrm{m})$ and $14(10.95-11.65 \mu \mathrm{m})$ of the ASTER GEDv3 dataset, and $c, c_{13}, c_{14}$ are empirical regression coefficients. For Landsat 5, these coefficients equal 0.0195, -0.0723, and 1.0521, respectively (Malakar et al. 2018).

For the NBEM approach, the actual $\varepsilon$ for each pixel was computed by adjusting the mean $\varepsilon$ in the ASTER GEDv3 by the fractional vegetation cover (FVC) 
estimated from the corresponding Landsat 5 data (Ermida et al., 2020). The FVC can be computed using the relationship from Carlson and Ripley (1997):

$$
\mathrm{FVC}=\left[\frac{\mathrm{NDVI}-\mathrm{NDVI}_{\text {bare }}}{\mathrm{NDVI}_{\mathrm{veg}}-\mathrm{NDVI}_{\text {bare }}}\right]^{2}
$$

Here NDVI is derived from the surface reflectances in the Near Infrared (NIR; 0.78-0.86 $\mu \mathrm{m}$ for ASTER and 0.77-0.9 $\mu \mathrm{m}$ for Landsat 5) and RED (0.63$0.69 \mu \mathrm{m})$ bands. $\mathrm{NDVI}_{\text {bare }}$ and $\mathrm{NDVI}_{\mathrm{veg}}$ are the reference NDVI for completely bare and completely vegetated pixels, respectively. $\mathrm{NDVI}_{\text {bare }}$ is set as 0.2 and $\mathrm{NDVI}_{\text {veg }}$ is equal to 0.86 based on previous estimates (Tang et al., 2010, Wang et al. 2015, Ren et al. 2017). The NDVI-adjusted $\varepsilon\left(\varepsilon_{\text {NDVI }}\right)$ was then calculated using the equation:

$$
\varepsilon_{\mathrm{NDVI}}=\mathrm{FVC} \varepsilon_{\mathrm{veg}}+(1-\mathrm{FVC}) \varepsilon_{\mathrm{bare}}
$$

Equation 5 is wavelength dependent, but for the Landsat 5 TIR band, $\varepsilon_{\text {veg }}$ [was set to 0.99 due to the small variability for vegetated surfaces (Peres and DaCamara, 2005), while $\varepsilon_{\text {bare }}$ is estimated from ASTER measurements (Ermida et al. 2020).

In addition to the options for specifying $\varepsilon$ included in the open-source GEE module (Ermida et al. 2020), we incorporate three additional methods, a CBEM approach using the average of the MODIS $\varepsilon$ for bands 31 and 32 ( $\left.\varepsilon_{\text {MODIS }}\right)$, and the NBEM approaches by Griend and Owe $\left(1993\right.$, $\left.\varepsilon_{\text {Griend }}\right)$ and Valor and Caselles 1996 ; $\left.\varepsilon_{\text {Valor }}\right)$. The value of $\varepsilon_{\text {Griend }}$ can expressed as:

$$
\varepsilon_{\mathrm{Griend}}=1.0094+0.047 \ln (\mathrm{NDVI})
$$

and $\varepsilon_{\text {Valor }}$ can be expressed as:

$$
\varepsilon_{\text {Valor }}=\varepsilon_{\mathrm{veg}} \mathrm{FVC}+\varepsilon_{\text {bare }}(1-\mathrm{FVC})+0.06 \mathrm{FVC}(1-\mathrm{FVC})
$$

The methods above attempt to capture the spatial variability in $\varepsilon$ using standard TES, CBEM, and NBEM approaches. To test the sensitivity of the LST derived for both urban and rural surfaces from the SMW algorithm, we 
also calculated global LST for different prescribed values of $\varepsilon$ from 0.88 to 1 with a step size of 0.02 .

Both to minimize computational costs and since the overall focus was the impact of different values of $\varepsilon$ on urban and rural LST, we used a single year (2010) of Landsat 5 data for the analysis. In the present study, the data used for estimation of $\varepsilon$, NDVI, and LST were first screened using cloud masking algorithms. For the NIR and RED bands, used to compute NDVI, both clouds and cloud shadows were removed based on the pixel-level quality flags. For TIR, only pixels with no cloud contamination were considered. Since different regions of the world can have different amounts and even seasonality of cloud cover, we attempted to minimize the impact of this inter-regional variability by focusing on summer and winter separately rather than annual means. Summers are defined as the months of June, July, and August in northern hemisphere and December, January, and February in the southern hemisphere, and vice versa for winter. This is consistent with the practice of separately studying the SUHI for summer and winter in the literature (Peng et al. 2011, Clinton and Gong, 2013 Chakraborty and Lee, 2019). Overall, based on this temporal subsetting, each pixel can have a maximum of 5 to 6 Landsat observations during the study period.

\subsection{Estimating surface urban heat islands}

To estimate the SUHI, we calculated the LST for pairs of urban and rural references for each of almost 10,000 urban agglomerations or clusters (Fig. 17) that form the base of the Yale Center for Earth Observation (YCEO) Global Surface UHI Dataset (Chakraborty and Lee, 2019). The original urban boundaries are based on global urban extent data derived from MODIS (Schneider et al. 2010 ). Note that the vast majority $(\approx 89 \%)$ of these clusters are in the northern hemisphere. We checked whether Landsat provides representative observations over the urban clusters after pixel-level cloud screening. Figure $1 \mathrm{~b}$ shows the percentage of the maximum possible pixels in each cluster with at least one observation from Landsat during northern hemisphere summer. Overall, after 
temporal compositing, the majority $(63.6 \%)$ of the clusters have complete spatial coverage from Landsat observations, with the percentage of available pixels ranging from a 5 th percentile value of $46.5 \%$ to a 95 th percentile of $100 \%$.

The delineation of urban and rural areas for SUHI quantification is not trivial. Here we used the Simplified Urban Extent (SUE) algorithm described in Chakraborty and Lee (2019). The SUE algorithm defines the SUHI of an urban cluster as the difference in mean LST of all urban pixels ( $\mathrm{LST}_{\text {urb }}$ ) and mean LST of all rural (non-urban and non-water) pixels ( $\mathrm{LST}_{\text {rur }}$ ) within the cluster, or:

$$
\mathrm{SUHI}=\mathrm{LST}_{\text {urb }}-\mathrm{LST}_{\text {rur }}
$$

By calculating both $\mathrm{LST}_{\text {urb }}$ and $\mathrm{LST}_{\text {rur }}$ from pixels within the cluster, the SUE algorithm avoids issues arising from somewhat arbitrary definitions of buffer widths when using commonly used buffer-based rural references (Zhou et al. 2015 Yang et al. 2019. Chakraborty and Lee, 2019). Moreover, not using a buffer around the urban area minimizes the impact of potential differences in atmospheric forcing between the urban core and the rural periphery (Li et al. 2018). This essentially describes the SUHI as a consequence of only the difference in surface climate response of urban and rural areas. The SUE method compares well against both other observational as well as theoretical estimates of SUHI (Niu et al. 2020, Manoli et al., 2020).

The SUE algorithm requires land cover datasets that can resolve urban and non-urban pixels within each cluster. The original implementation of the algorithm developed by Chakraborty and Lee (2019) was based on $1 \mathrm{~km}$ resolution MODIS Terra and Aqua measurements (Wan et al., 2006), with the urban and rural land cover resolved using the $500 \mathrm{~m}$ MODIS land cover product (Strahler, 1999). Since both Landsat 5 and ASTER GEDv3 are at finer resolutions, we need suitable higher resolution datasets. To resolve urban pixels, we used one of the highest resolution global urban land cover products currently available, the Global Urban Footprint (GUF) dataset (Esch et al. 2017), which is available at $12 \mathrm{~m}$ resolution. The GUF dataset is generated by an automated unsuper- 
vised classification scheme using over 180,000 high resolution (3 m) radar images from 2011 and 2012 and shows an overall accuracy of $85 \%$ compared to absolute ground truth data. We use Landsat 5 for calculating LST since the only other Landsat product available for the years of validity of the GUF dataset, Landsat 7, has data gaps due to failure of the Scan Line Corrector (SLC), which limits its use. For calculating both $\mathrm{LST}_{\text {urb }}$ and $\mathrm{LST}_{\text {rur }}$, water pixels were first removed based on the Joint Research Center (JRC) $30 \mathrm{~m}$ global surface water dataset (Pekel et al., 2016). All remaining GUF pixels within the urban clusters were then used to calculate $\mathrm{LST}_{\text {urb }}$. Similarly, for $\mathrm{LST}_{\text {rur }}$, we considered all nonGUF and non-water pixels within each urban cluster. Since terrain height has a significant impact on LST, for each urban cluster, we also masked out rural pixels when its altitude difference from the median altitude of all urban pixels exceeded $50 \mathrm{~m}$ using the Global Multi-resolution Terrain Elevation Data 2010 (GMTED2010) (Danielson and Gesch, 2011). Overall, the percentage of pixels in each urban cluster that is urban varies between a 5 th percentile of $9.1 \%$ to a 95th percentile of $74.3 \%$ (Fig. 1c).

Our final units of calculation are the urban clusters, each of which have summertime and wintertime values of SUHI from ASTER emissivity ( $\mathrm{SUHI}_{\mathrm{ASTER}}$ ) and the NDVI-adjusted emisivity $\left(\mathrm{SUHI}_{\mathrm{NDVI}}\right)$, as well as the intermediate variables, including $\mathrm{LST}_{\text {urb,ASTER}}, \mathrm{LST}_{\text {urb,NDVI }}, \mathrm{LST}_{\text {rur,ASTER }}, \mathrm{LST}_{\text {rur,NDVI}}, \varepsilon_{\text {urb,ASTER, }}$ $\varepsilon_{\text {urb,NDVI}}, \varepsilon_{\text {rur,ASTER, and }} \varepsilon_{\text {rur,NDVI }}$. We also include the corresponding variables for the prescribed $\varepsilon$ values of 0.88 to 1 and the other approaches for prescribing $\varepsilon$ (Snyder et al., 1998, Van de Griend and OWE, 1993, Valor and Caselles, 1996). Since the native resolution of Landsat 5 TIR is $120 \mathrm{~m}$, ASTER is $90 \mathrm{~m}$, GUF is $12 \mathrm{~m}$, and JRC surface water is $30 \mathrm{~m}$, all calculations for spatial averaging are done after re-gridding all products to $60 \mathrm{~m}$ using nearest neighbor resampling. Although this resampling would introduce biases when calculating thermal radiance at finer scales (Zhan et al., 2013, Bonafoni et al., 2016), this issue is minimized by averaging the SUHI for the whole cluster instead of calculating intra-urban variability. Moreover, this error would be common to all the approaches used. 


\subsection{Comparison with MODIS data}

Almost all past multi-city studies on the SUHI have used MODIS $1 \mathrm{~km}$ LST observations (Zhang et al. 2010, Peng et al., 2011, Clinton and Gong, 2013, Chakraborty and Lee, 2019, Yao et al., 2019, Chakraborty et al., 2020). This is both due to the more frequent return period of MODIS compared to Landsat, which helps with cloud screening ( $\mathrm{Hu}$ and Brunsell, 2013), and the availability of nighttime values, thus allowing inferences about diurnal patterns. Since here we provide global estimates of SUHI based on different $\varepsilon$ assumptions, it is important to compare these estimates with MODIS-based values. We calculate the SUHI using the SUE algorithm using the same urban and rural separation and the MODIS Terra $1 \mathrm{~km}$ daytime LST for 2010. MODIS Terra is chosen over Aqua since its equatorial crossing time $(\approx 10: 30 \mathrm{am})$ is comparable to that for Landsat $5(\approx 9: 45 \mathrm{am})$. The MODIS LST is based on $\varepsilon$ values generated from a CBEM aproach (Snyder et al., 1998).

For this comparison, all analysis is done at a scale of $60 \mathrm{~m}$, identical to the Landsat-based analysis using the same land cover data. This is done to ensure that the differences stem only from the MODIS versus Landsat data. Since the LST estimates from both MODIS and Landsat have uncertainties, we use reduced major axis or geometric mean regression instead of ordinary least square (OLS) regression, with Landsat data as the dependent variable and MODIS data as the independent variable. Metrics of comparison include the coefficient of determination $\left(r^{2}\right)$, the RMSE, and the mean bias error (MBE). Note that the MODIS-derived values are considered to be the baseline (or independent variable), not because they represent the 'truth', but because they have been traditionally used to estimate the SUHI at global scales (Peng et al., 2011, Clinton and Gong, 2013, Chakraborty and Lee, 2019). This allows insightful comparisons with the existing SUHI literature.

\subsection{Regions of interest}

In addition to examining the SUHI globally, we separately examine the influence of $\varepsilon$ on the the calculated SUHI for each of the five Koppen Geiger 
climate zones, namely tropical, arid, temperate, boreal, and polar Rubel and

320 Kottek, 2010). These broad classes divide the Earth's land surface into regions

321 with large variabilities in vegetation patterns and incoming radiation. Both

322 modeling and observational studies have noted the influence of the background

323 climate on the SUHI intensity (Zhao et al., 2014, Chakraborty and Lee, 2019).

${ }_{324}$ Figure 13 shows the centroids of all the urban clusters and the climate zone

325 they belong to. Note that due to cloud cover or the lack of valid urban or rural

326 pixels within a cluster, we do not get a SUHI value for all the urban clusters

327 in each case. For instance, during summer, there are 9063 clusters based on

328 ASTER observations and 9010 from the NBEM approach. Similarly, during

329 winter, there are 8206 clusters from ASTER and 7943 after adjusting by NDVI. 


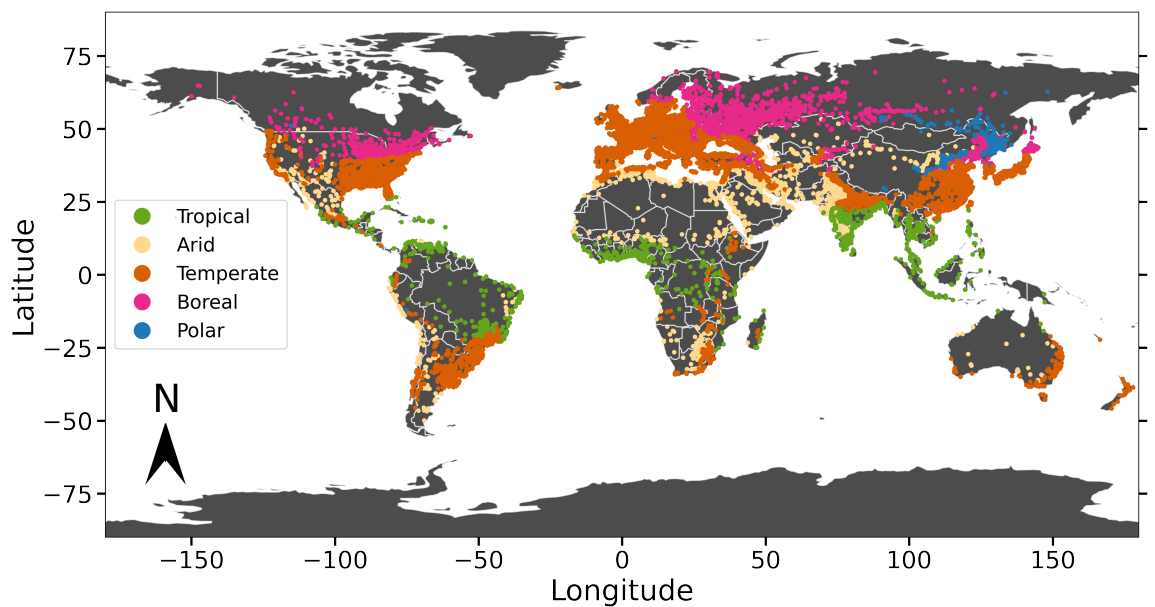

b

c
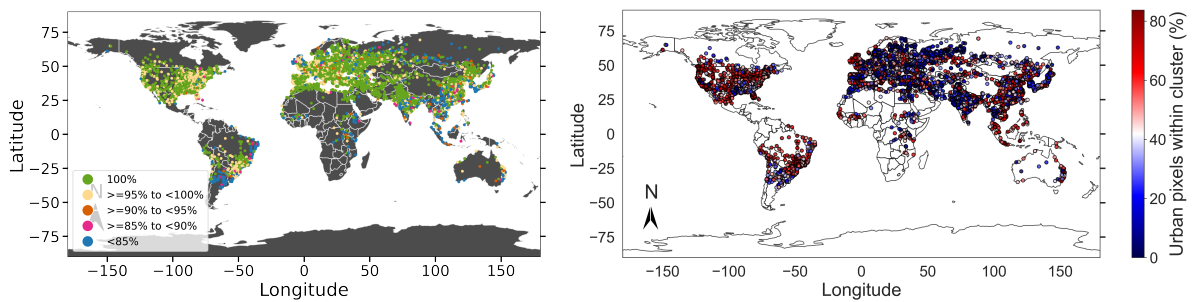

Figure 1: Urban clusters considered in the present study. Sub-figure (a) shows the centroids of every cluster and the climate zones they belong to. Sub-figure (b) shows the percentage of available pixels from the Landsat observations after temporal compositing compared to the maximum number of pixels possible within each cluster during the northern hemisphere summer of 2010. Sub-figure (c) shows the percentage of total pixels in each cluster that are urban at the $60 \mathrm{~m}$ resolution during the same time period.

\section{Results}

\subsection{Impact of adjusting emissivity by vegetation on urban and rural land surface} temperature

Figures $2 \mathrm{a}$ and $2 \mathrm{~b}$ show bar plots of $\varepsilon_{\text {urb }}$ and $\varepsilon_{\text {rur }}$ derived using ASTER data and the NDVI-adjusted approaches. Results are shown for both summer and winter and also divided into each of the Koppen Geiger climate zones. The 
ASTER $\varepsilon_{\text {urb }}$ varies from 0.966 for tropical climate to 0.969 in temperate climate.

For $\varepsilon_{\text {rur }}$, there is a slightly higher range of values, with the minimum value still at 0.966 for tropical climate, but a maximum of 0.970 for temperate and boreal climate. Note that the ASTER data are multi-year averages and thus do not have different values for summer and winter. Both at the global scale and for all climate zones other than arid, $\varepsilon_{\text {urb,ASTER }}$ is less than $\varepsilon_{\text {rur,ASTER }}$. When $\varepsilon$ is adjusted using NDVI, we see the variability between the seasons. The global mean values are higher for summer than for winter $\left(\varepsilon_{\text {urb,NDVI }}=0.971\right.$ and $\varepsilon_{\mathrm{rur}, \mathrm{NDVI}}=0.975$ for summer; $\varepsilon_{\mathrm{urb}, \mathrm{NDVI}}=0.969$ and $\varepsilon_{\mathrm{rur}, \mathrm{NDVI}}=0.970$ for winter). In summer, $\varepsilon_{\text {rur,NDVI }}$ varies from 0.969 in arid climate to 0.977 in boreal climate. Expectedly, $\varepsilon_{\text {urb,NDVI }}$ has less variability, ranging from 0.968 in tropical climate to 0.972 in boreal climate. For winter, there is less variability, evidently because vegetation differences between the climate zones, which control this variability, are suppressed. During this season, $\varepsilon_{\text {rur,NDVI }}$ varies from 0.969 in polar climate to 0.971 in temperate climate and $\varepsilon_{\text {urb,NDVI }}$ varies from 0.967 in tropical to 0.970 in boreal climate. Overall, $\varepsilon_{\text {urb }}$ after adjusting for NDVI is still lower than $\varepsilon_{\text {rur }}$. Moreover, particularly for the rural references, the NDVIadjusted $\varepsilon$ is usually higher than the ASTER observations since vegetation tends to have a higher $\varepsilon$ than bare soil.

Figures $2 \mathrm{r}$ and $2 \mathrm{~d}$ show the corresponding daytime $\mathrm{LST}_{\text {urb }}$ and $\mathrm{LST}_{\text {rur }}$ using the two approaches and for the two seasons. The daytime LST values are evidently driven almost entirely by the energy availability across seasons and climate zones, with the summer mean daytime LST being highest in arid regions $\left(\mathrm{LST}_{\text {rur,NDVI }}=40.56{ }^{\circ} \mathrm{C}\right)$ and the winter mean daytime LST being lowest in polar $\left(\mathrm{LST}_{\text {rur,NDVI }}=-10.55{ }^{\circ} \mathrm{C}\right)$ and boreal climate $\left(\mathrm{LST}_{\text {rur,NDVI }}=-9.81{ }^{\circ} \mathrm{C}\right)$. Urban areas are not evenly distributed globally, with the majority being in the global north but very few in the high latitudes. This explains why the wintertime mean daytime LST is closer for polar and boreal climate than would be expected for regional means. Tropical areas show the least difference between summer daytime LST $\left(\operatorname{LST}_{\text {rur,NDVI }}=32.04{ }^{\circ} \mathrm{C}\right)$ and winter daytime LST $\left(\mathrm{LST}_{\text {rur,NDVI }}\right.$ $=30.54{ }^{\circ} \mathrm{C}$ ) since they do not have strong seasonal cycles. The urban daytime 
367 LST values are usually higher than the rural daytime LST values, representing

368 the daytime SUHI intensity. Note that there are some differences between the

369 number of available $\varepsilon$ observations from the ASTER multi-year composites and

370 the NDVI-adjusted value for 2010 due to cloud contamination of the Landsat 371 observations. 

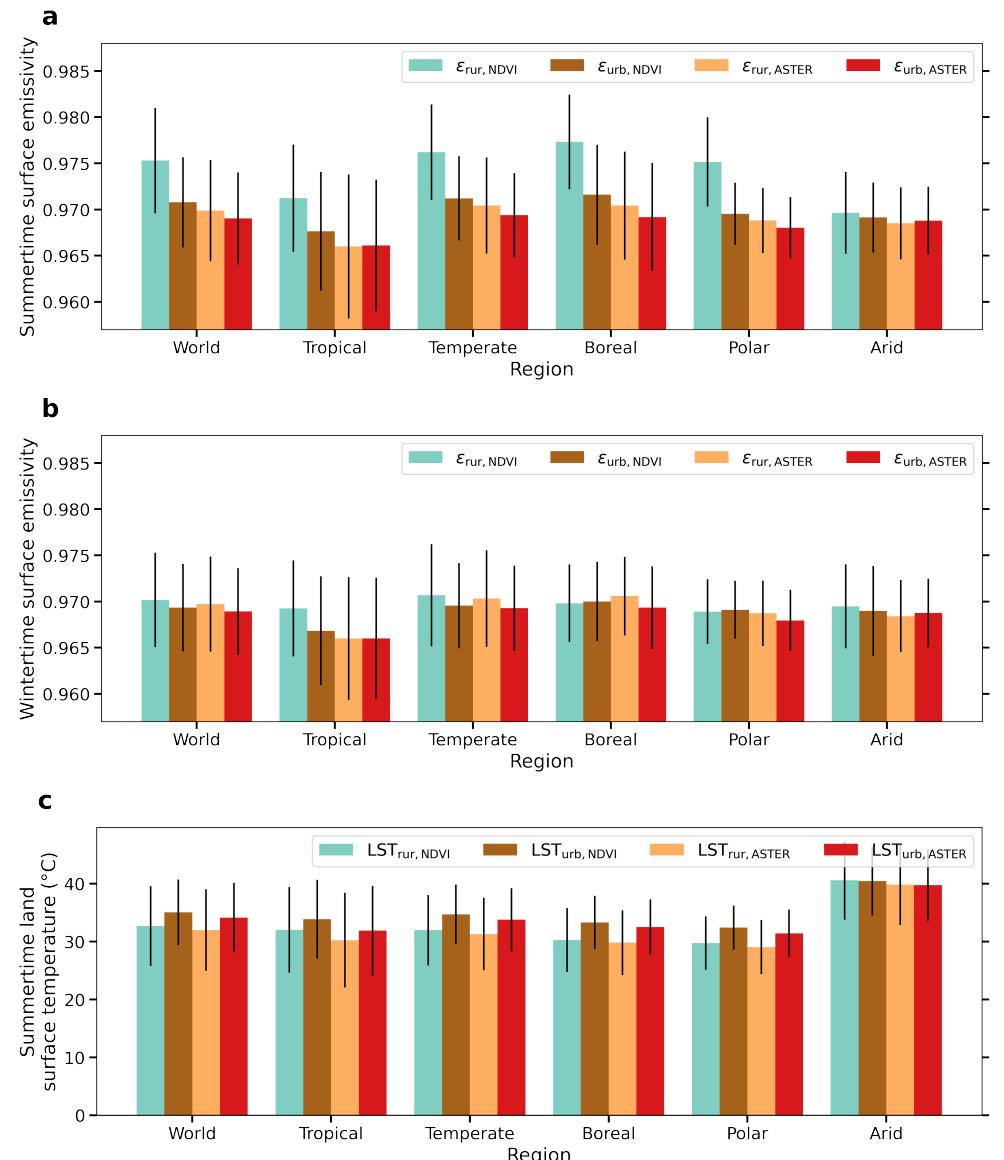

d

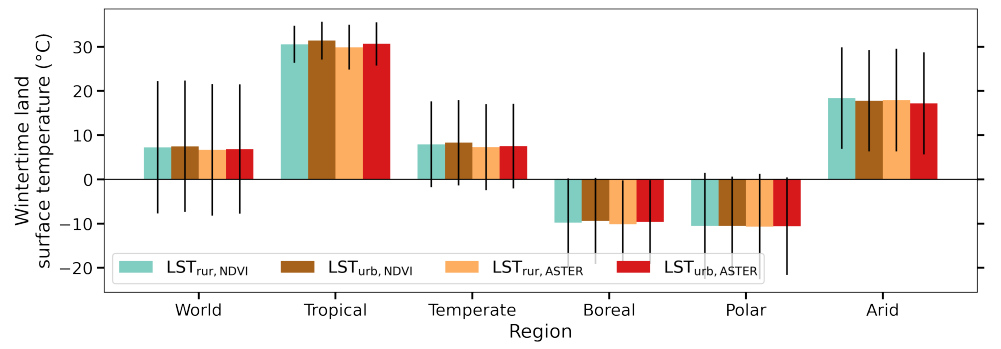

Figure 2: Mean and standard deviation of surface emissivity ((a) and (b)) and daytime land surface temperature ((c) and (d)) for all urban and rural clusters and for each climate zone. Values are shown separately for summer and winter for both the ASTER-based and NDVI-adjusted methods. 


\subsection{Impact on the surface urban heat island intensity}

Figure 3 shows the impact of adjusting $\varepsilon$ by NDVI on the daytime SUHI intensity. The global estimates and the climate zone means are shown along with the percentage difference between the two estimates. Note that the percentage difference in LST depends on the unit used since LST units have different scales. However, this issue disappears when calculating the percentage changes in SUHI since the values are always subtracted from a rural reference in the same temperature scale. Regardless, it is important to be careful when examining percentage changes in variables like SUHI, which have a low signal. To avoid uncertainties arising from sampling differences, we only use the urban clusters for which we get daytime SUHI estimates from both methods. This leaves 9010 clusters during summer and 7943 during winter. During summer, the daytime $\mathrm{SUHI}$ is highest for boreal climate $\left(\mathrm{SUHI}_{\mathrm{ASTER}}=2.71{ }^{\circ} \mathrm{C} ; \mathrm{SUHI}_{\mathrm{NDVI}}=3.03\right.$ ${ }^{\circ} \mathrm{C}$ ) and lowest for arid climate $\left(\mathrm{SUHI}_{\mathrm{ASTER}}=-0.09{ }^{\circ} \mathrm{C} ; \mathrm{SUHI}_{\mathrm{NDVI}}=-0.10{ }^{\circ} \mathrm{C}\right)$, with a global mean of $2.15{ }^{\circ} \mathrm{C}\left(\mathrm{SUHI}_{\mathrm{ASTER}}\right)$ to $2.37^{\circ} \mathrm{C}\left(\mathrm{SUHI}_{\mathrm{NDVI}}\right)$. For winter, the global mean daytime SUHI ranges from $0.18{ }^{\circ} \mathrm{C}\left(\mathrm{SUHI}_{\mathrm{ASTER}}\right)$ to $0.24{ }^{\circ} \mathrm{C}$ $\left(\mathrm{SUHI}_{\mathrm{NDVI}}\right)$, with the lowest $\mathrm{SUHI}$ seen for arid urban clusters $\left(\mathrm{SUHI}_{\mathrm{ASTER}}=\right.$ $\left.-0.74{ }^{\circ} \mathrm{C} ; \mathrm{SUHI}_{\mathrm{NDVI}}=-0.61{ }^{\circ} \mathrm{C}\right)$. Tropical urban clusters show the highest winter daytime SUHI $\left(\mathrm{SUHI}_{\mathrm{ASTER}}=0.75{ }^{\circ} \mathrm{C} ; \mathrm{SUHI}_{\mathrm{NDVI}}=0.84{ }^{\circ} \mathrm{C}\right)$. Both seasonal and climatic trends are consistent with previous estimates (Clinton and Gong, 2013, Zhao et al. 2014, Chakraborty and Lee, 2019). 


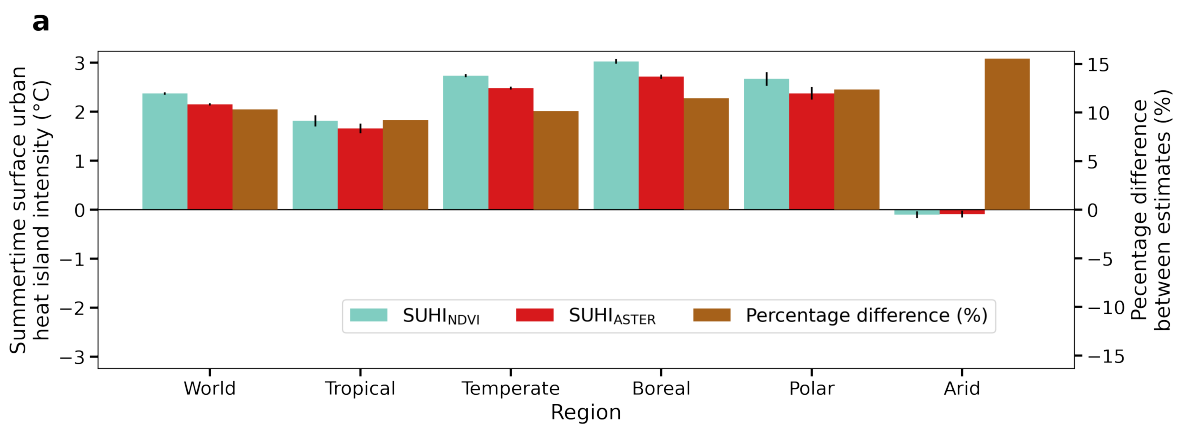

b

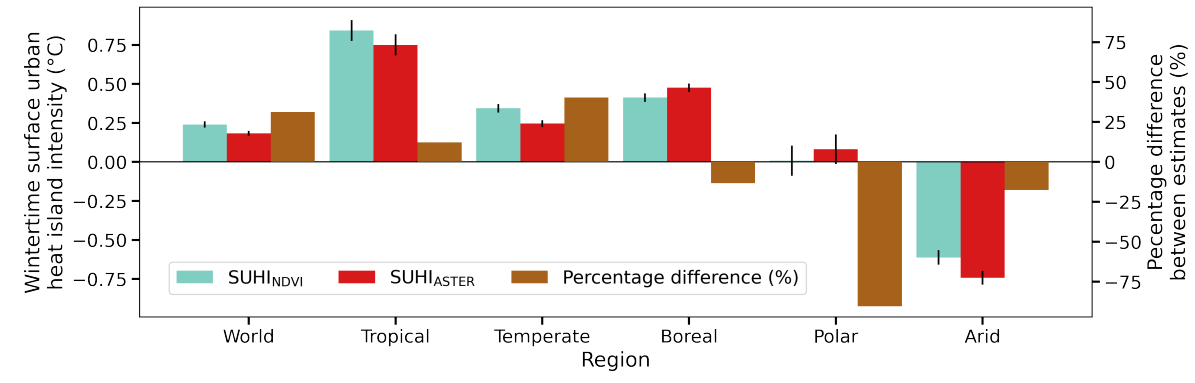

Figure 3: Mean and standard error of daytime surface urban heat island intensity based on both the ASTER-based and NDVI-adjusted surface emissivity $(\varepsilon)$ assumptions for (a) summer and (b) winter. Percentage changes in estimated value when switching from ASTER to NDVI-adjusted $\varepsilon$ is shown on the right y axis.

The SUHI derived from NDVI-adjusted estimates of $\varepsilon$ are generally higher since the $\Delta \varepsilon$ increases when vegetation is considered (Fig. 2). This is particularly true for summer, with SUHI increasing in magnitude by $9.2 \%$ in tropical urban clusters to $15.5 \%$ in arid clusters. Globally, the summertime increase in daytime SUHI is around $10.6 \%$ when moving from ASTER $\varepsilon$ to NDVI-adjusted $\varepsilon$. For winter, there is more variability in both magnitude and direction of percentage change, though this is partly driven by the baseline SUHI already being low. The global percentage increase in magnitude is $31.2 \%$, with an increase of $40.2 \%$ in temperate urban clusters. Boreal, polar, and arid urban clusters show a decrease in SUHI when the NDVI-adjusted $\varepsilon$ is used by $13.3 \%, 90.5 \%$, and $17.6 \%$, respectively. 


\subsection{Other approaches for prescribing emissivity}

All the other approaches for prescribing $\varepsilon$ considered here (Figs 4 and $4 \mathrm{~b}$ ) show patterns similar to those seen for $\varepsilon_{\text {ASTER }}$ and $\varepsilon_{\text {NDVI }}$ earlier. The value of $\varepsilon_{\text {urb }}$ is lower than $\varepsilon_{\text {rur }}$ for all methods and these differences are minimized during winter. Most of the approaches did not show any physically impossible $\varepsilon$ value. However, roughly $0.55 \%$ of the cluster-averaged $\varepsilon_{\text {Valor }}$ values were greater than 1. These were removed. Overall, the NBEM approach by Griend and Owe (1993) is the clear outlier, with higher contrasts between urban and rural $\varepsilon$ and lower values of $\varepsilon$ overall. Consequently, the SUHI values are similar for most methods other than when using $\Delta \varepsilon_{\text {Griend }}$ (Figs 4 and $4 \mathrm{~d}$ ). For winter in particular, the SUHI from that method are several times higher than the other ones. The patterns across climate zones are also captured well by all the approaches with the exception of $\varepsilon_{\text {Griend }}$ based SUHI showing atypical positive values over arid areas. Using $\varepsilon_{\text {Griend }}$ to compute rural LST has been found to show the highest RMSE compared to observations in a recent multi-model comparison (Sekertekin and Bonafoni, 2020a).
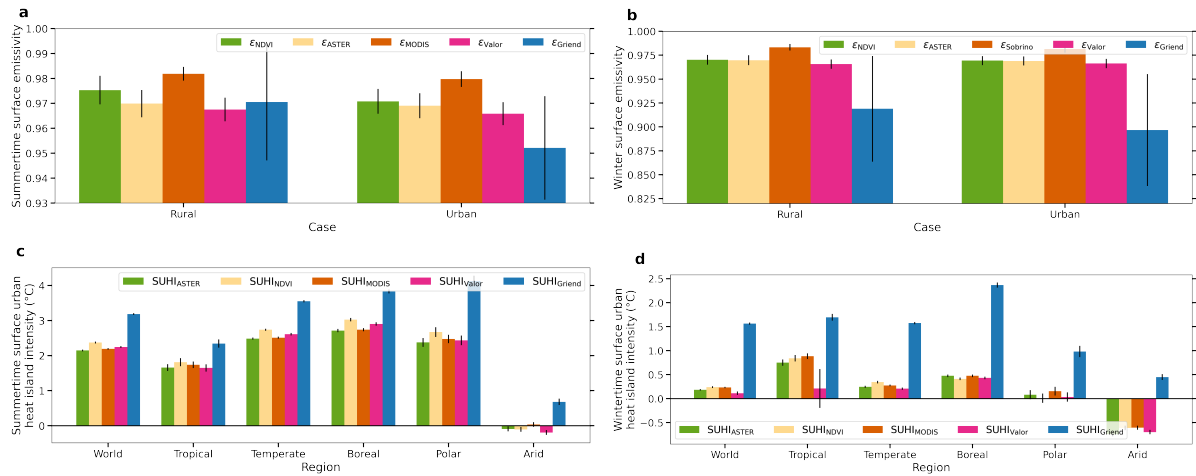

Figure 4: Sub-figures (a) and (b) show the mean and standard deviation of urban and rural surface emissivity $(\varepsilon)$ for summer and winter, respectively, from all the approaches considered in the present study. Sub-figures (c) and (d) show the mean and standard error of surface urban heat island intensity for summer and winter, respectively, for the world and all climate zones using the different methods of prescribing $\varepsilon$. 


\subsection{Global Spatial Patterns of Surface Urban Heat Island}

Figures 2, 3, 4 show bulk patterns. Since the urban cluster-level information, including their location, are important, we also show the spatial plots of the urban locations and the SUHI intensity (Fig. 5). Here we only use the common urban clusters with data from all five approaches for prescribing $\varepsilon$, representing an ensemble estimate of SUHI. The summertime patterns for the climate zones are generally replicated in the global maps, with the lowest, mainly negative values, in arid and semi-arid regions in the Middle East, Saharan Africa, southern US and northern Mexico, central Australia, and South America (Fig 5a). The rest of the world generally shows a positive SUHI intensity. India shows a mixed pattern, with western and central parts showing negative values and northern and southern edges showing positive SUHI, which is consistent with the summer daytime patterns found in Kumar et al. (2017). Overall, the urban cluster ensemble mean SUHI intensity varies between a 5 th percentile value of $-1.97{ }^{\circ} \mathrm{C}$ to a 95 th percentile of $5.65{ }^{\circ} \mathrm{C}$. As also seen in the earlier subsection, the range of daytime ensemble SUHI during winter is smaller (5th percentile of $-1.83{ }^{\circ} \mathrm{C}$ to 95 th percentile of $2.32{ }^{\circ} \mathrm{C}$ ). The contrast between urban clusters in dry versus other climate zones is still apparent, though the positive SUHI values are less extreme. 
a

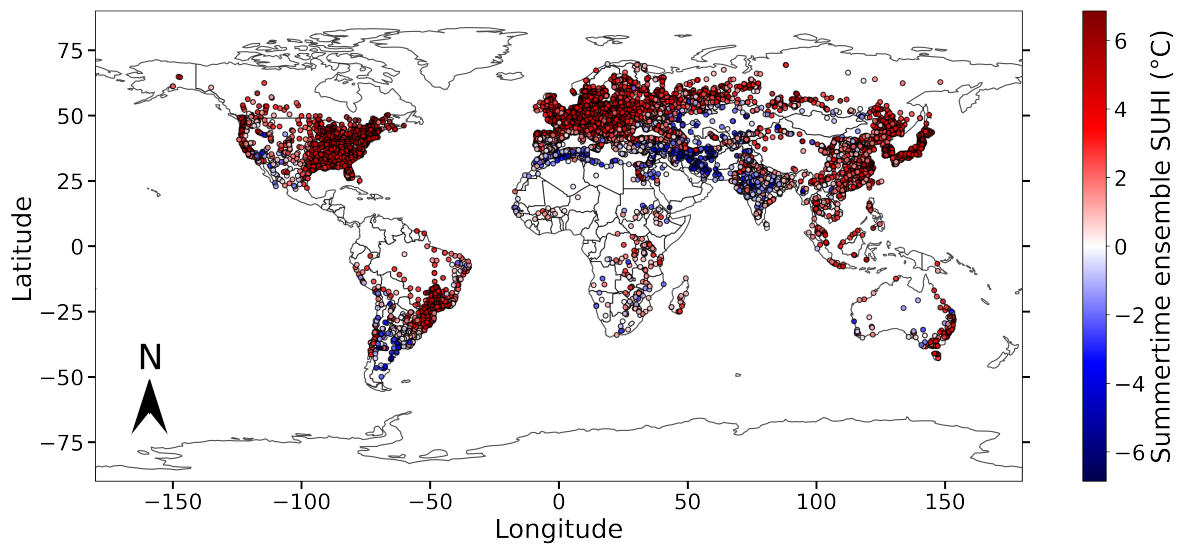

b
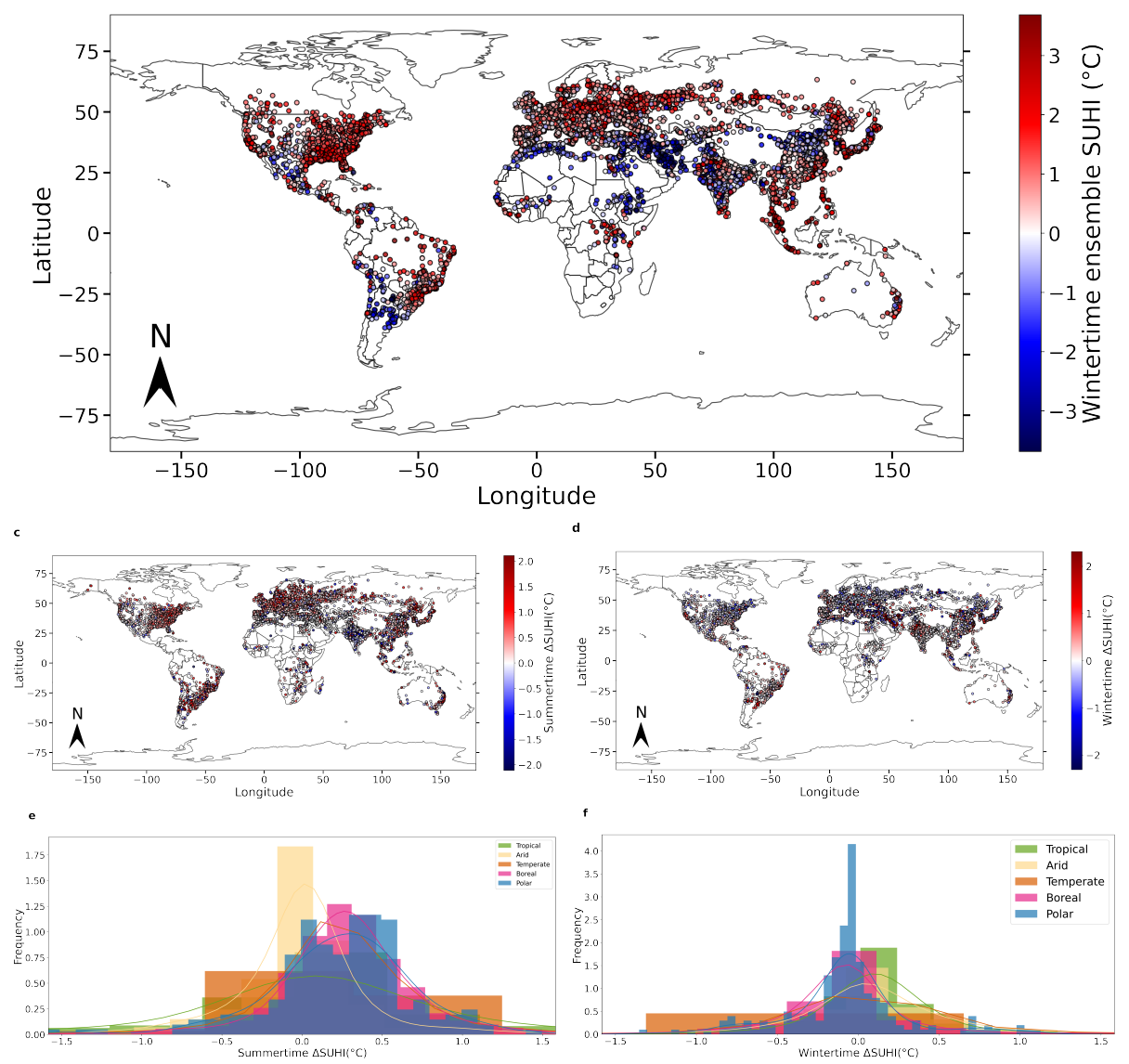

Figure 5: Location of urban clusters and their daytime ensemble mean surface urban heat island intensity (SUHI) estimated from Landsat for summer (a) and winter (b). Sub-figures (c) and (d) show the the urban cluster level difference in estimated SUHI after adjusting the surface emissivity using NDVI for summer and winter, respectively. Sub-figures (e) and (f) show the distribution of these differences during summer and winter for each climate zone. 
We also examine how using $\varepsilon_{\text {NDVI }}$ instead of $\varepsilon_{\text {ASTER }}$ influences the SUHI by calculating the difference in SUHI $(\Delta \mathrm{SUHI})$ between the two methods (Figs 5 and $5 \mathrm{~d})$. Although the overall $\Delta \mathrm{SUHI}$ is positive, there is a range of values. During summer, $\Delta \mathrm{SUHI}$ ranges from a 5 th percentile of $-0.59{ }^{\circ} \mathrm{C}$ to a 95th percentile of $1.06{ }^{\circ} \mathrm{C}$ and during winter, it ranges from -0.74 to $0.94{ }^{\circ} \mathrm{C}$. Interestingly, many of the urban clusters that show a positive $\Delta$ SUHI during summer show a negative anomaly during winter. This includes urban clusters over Europe, northeast US, and parts of northern China. Similarly, urban clusters over India, a few over the Amazon, and parts of southeast Asia show positive $\Delta$ SUHI anomalies during winter and negative values during summer. This is consistent with the patterns seen in Fig. 3 3 , with tropical and temperate urban clusters showing a percentage increase in winter daytime SUHI when using NDVI-adjusted $\varepsilon$ and boreal, polar, and arid urban clusters showing a percentage decrease in magnitude. We also show the density plots of $\Delta$ SUHI during summer and winter (Figs 5 and 5 ). Overall, the differences between two methods is minimal for urban clusters in arid climate during summer and for polar urban clusters in winter. In contrast, the positive differences between $\varepsilon_{\mathrm{NDVI}}$ and $\varepsilon_{\mathrm{ASTER}}$ are most pronounced in tropical areas during winter. 

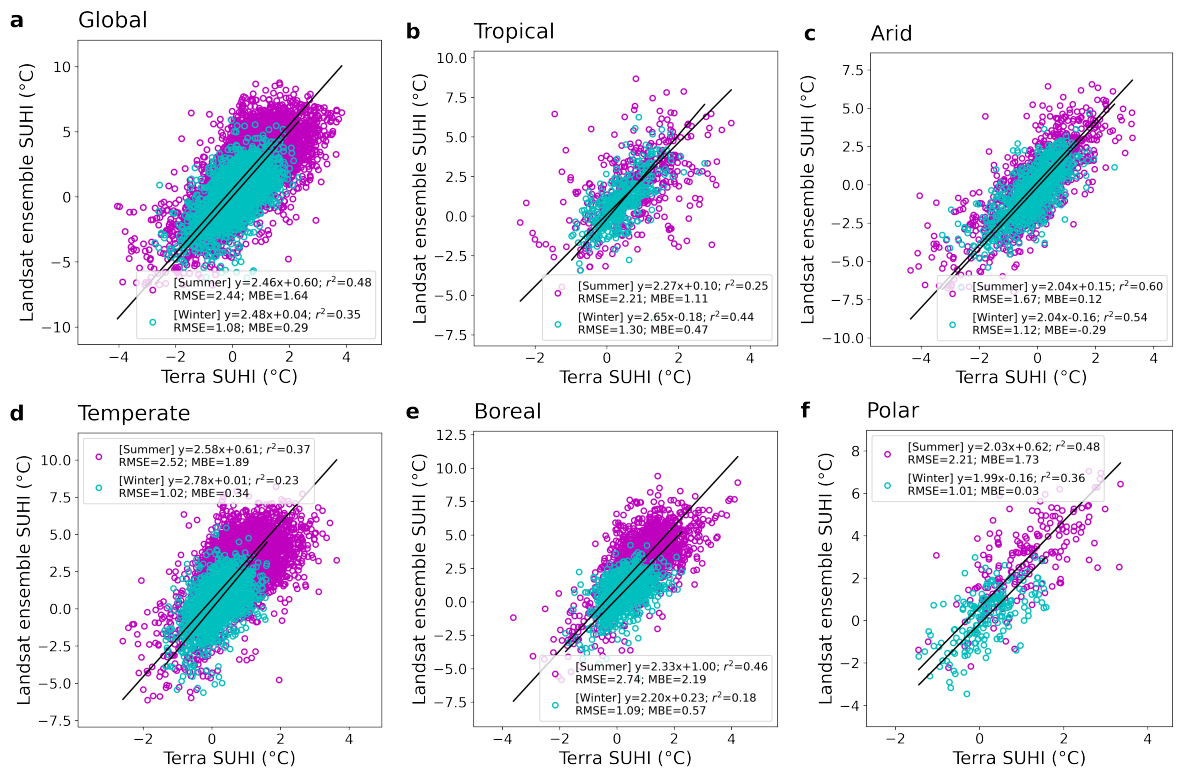

Figure 6: Scatterplots of Landsat versus MODIS-derived daytime summer surface urban heat island intensities for (a) all clusters and for each climate zone, namely (b) tropical, (c) arid, (d) temperate, (e) boreal, and (f) polar. Each point represents one cluster and the equations for the lines of best fit, the coefficients of determination, and the mean bias and root mean square errors between the two estimates are annotated. The global sample size is 7314 , with $424,1093,4089,1549$, and 200 clusters lying in the tropical, arid, temperate, boreal, and polar climate zones, respectively.

We compare our Landsat-derived ensemble estimates of daytime SUHI with the MODIS Terra-derived estimates, both globally, and for each climate zone. The scatter plots, where each point represents the daytime SUHI for one urban cluster, are shown for summer and winter (Fig. 6). The plots show the lines of best fit and the metrics of evaluation and the sample sizes for each case are in the figure captions. Overall, the Landsat-derived daytime SUHI estimates show a moderately strong positive relationship with the MODIS-derived estimates during summer (global $r^{2}=0.48$ ), and a somewhat weaker relationship during winter (global $r^{2}=0.35$ ). For the summer, the $r^{2}$ values are highest for arid 
urban clusters $\left(r^{2}=0.60\right)$ and lowest for tropical urban clusters $\left(r^{2}=0.25\right.$; Fig.

6. This is unsurprising since, even after choosing only clear-sky pixels, the data availability due to the difference in cloud cover between the two satellites, driven by the distinct return periods, would be higher over tropical areas and lowest over arid regions (Chakraborty et al. 2020) (see Discussion). During winter, $r^{2}$ values are still highest for arid urban clusters (0.54), but lowest in boreal climate (0.18; Fig. 6). Unlike most other climate zones, tropical areas show an improved $r^{2}$ between MODIS and Landsat SUHI from summer to winter. This could be because a large fraction of the tropical urban clusters (Fig. 1) are located in regions with summer monsoon systems, which enhance precipitation and cloud cover (Zhisheng et al., 2015; Turner et al., 2020) and thus interfere with satellite observations of LST.

During summer, the SUHI calculated from Landsat is higher (in absolute magnitude) than that from MODIS (Figs 6). Assuming MODIS to be the baseline, both MBE and RMSE are highest for boreal climate zone $\left(2.19{ }^{\circ} \mathrm{C}\right.$ and $2.74{ }^{\circ} \mathrm{C}$, respectively) and lowest for arid urban clusters $\left(0.12{ }^{\circ} \mathrm{C}\right.$ and $1.67{ }^{\circ} \mathrm{C}$, respectively). During winter, the differences are generally lower, with the global $\mathrm{MBE}$ of $0.29^{\circ} \mathrm{C}\left(\mathrm{RMSE}=1.08^{\circ} \mathrm{C}\right)$. Among the climate zones, the boreal climate shows the greatest difference between Landsat and MODIS-derived SUHI (MBE $\left.=0.57^{\circ} \mathrm{C}\right)$. Overall, the wintertime SUHI magnitudes are similar from both satellites although there are large differences in their distributions. 
a

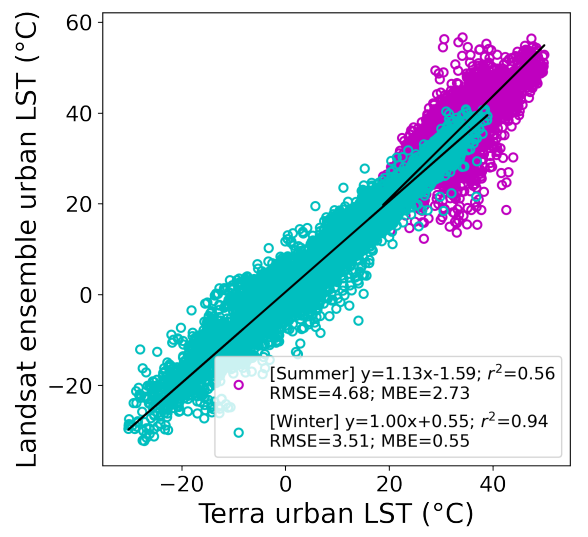

C

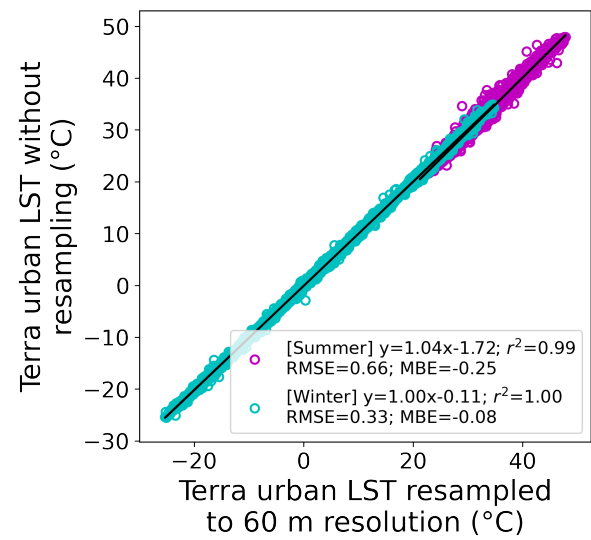

b

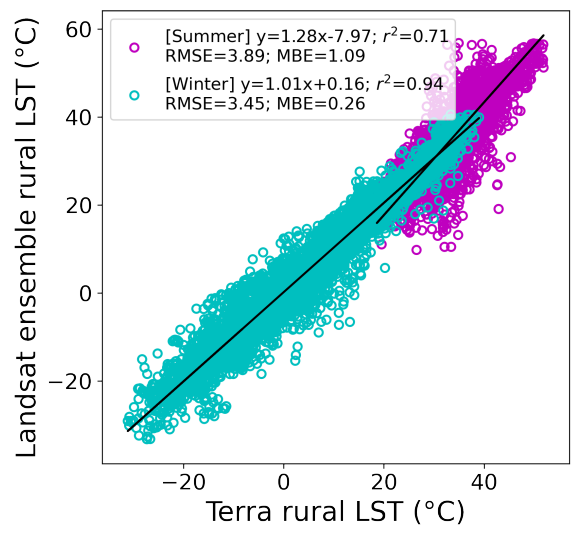

d

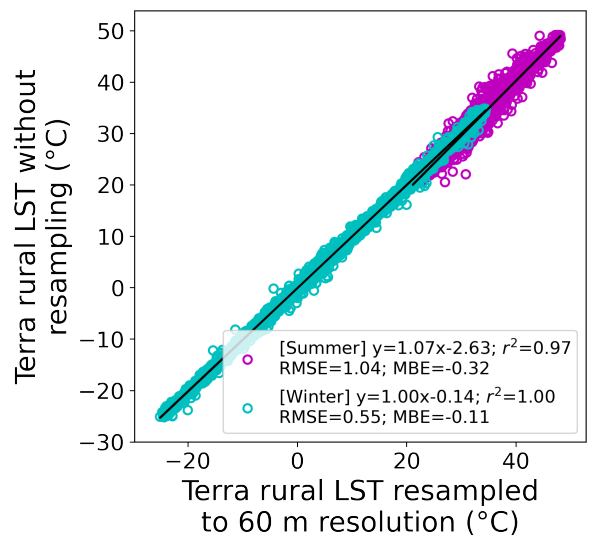

Figure 7: Scatterplots of Landsat versus MODIS-derived daytime urban ((a)) and rural ((b)) land surface temperature for all clusters for summer and winter. Each point represents one cluster and the equations for the lines of best fit, the coefficients of determination, the mean bias and root mean square errors between the two estimates are annotated. The sample size is 7315 for these cases. Sub-figures (c) and (d) show the MODIS-derived urban and rural LST for summer and winter before and after resampling to $60 \mathrm{~m}$. The sample size is 6020 for these cases.

Given the general overestimation in Landsat-derived summer daytime SUHI, it is necessary to check whether this is due to the higher resolution of the Landsat data which enables better separation of the urban-rural temperature differential or a systematic overestimation in Landsat LST. We examine this by separately 
evaluating $\mathrm{LST}_{\text {urb }}$ and $\mathrm{LST}_{\text {rur }}$ corresponding to all the urban clusters, shown in Figs $7 \mathrm{a}$ and $7 \mathrm{~b}$. For summer, although $\mathrm{LST}_{\text {rur }}$ is slightly higher in the Landsat data $\left(\mathrm{MBE}=1.09{ }^{\circ} \mathrm{C}\right.$ for $)$, the difference for $\mathrm{LST}_{\mathrm{urb}}$ is much higher $(\mathrm{MBE}=$ $2.73{ }^{\circ} \mathrm{C}$ ). During winter, the Landsat based LST is is closer to the MODIS-based value in both urban clusters $\left(\mathrm{MBE}=0.55^{\circ} \mathrm{C}\right)$ and their rural references $(\mathrm{MBE}$ $=0.26{ }^{\circ} \mathrm{C}$ ). This analysis generally shows that the deviations between MODIS and Landsat LST are not systematic over both urban and rural areas, and that urban areas show additional differences between the two satellites, particularly during summer. This is probably because Landsat data can resolve the thermal signature of urban areas better than MODIS. We also examine the impact of resampling the MODIS data to $60 \mathrm{~m}$ from its native $\approx 1000 \mathrm{~m}$ resolution on the cluster-mean LST values. The differences in the MODIS LST at the two resolutions is negligible, with $r^{2}$ values close to 1 . Although the MODIS LST $\mathrm{urb}_{\mathrm{u}}$ and $\mathrm{LST}_{\text {rur }}$ values at the native resolution are slightly lower than that after resampling, since the direction of the bias is consistent in direction for both cases, this will have minimal impact on the comparison of SUHI values derived from the two products.

\subsection{Sensitivity analysis}

We estimate the sensitivity of $\operatorname{LST}_{\text {urb }}$ and $\operatorname{LST}_{\text {rur }}$ to $\varepsilon$ and examine how that would impact SUHI estimates using OLS regressions. Since LST is a linear function of $\varepsilon$ in the SMW algorithm (Eq. 2), we get perfect linear relationships in all cases (Fig. 8), with LST decreasing as $\varepsilon$ increases. The slope of the lines of best fit give the sensitivity of LST to $\varepsilon$. The sensitivities are pretty similar for $\mathrm{LST}_{\mathrm{urb}}$ and $\mathrm{LST}_{\text {rur }}$ for both summer and winter with a value of around -59 ${ }^{\circ} \mathrm{C}$ for a unit change in $\varepsilon$. This linear sensitivity is a consequence of the linear approximation used in the SMW algorithm and is generally valid for the wavelength channel and within the range of temperature we observe on the Earth's land surface. Different algorithms used to estimate LST from satellite observations use different approximations and would yield slightly different sensitivities. 
${ }_{521}$ If we re-arrange the Stefan-Boltzmann law, given by:

$$
L_{\uparrow}=\varepsilon \sigma \mathrm{LST}^{4}
$$

${ }_{522}$ where $\sigma$ is the Stefan-Boltzmann constant $\left(5.67 \times 10^{-8} \mathrm{~W} \mathrm{~m}^{-2} \mathrm{~K}^{-4}\right)$ and $L_{\uparrow}$

${ }_{523}$ is the emitted thermal radiation from the surface, for a given $L_{\uparrow}$, LST is a

${ }_{524}$ power function of $\varepsilon$ with it theoretically approaching infinity as $\varepsilon$ approaches 0 .

525 In contrast, the SMW algorithm shows theoretical temperature values of 87.95

526 and $64.38{ }^{\circ} \mathrm{C}$ for rural surfaces with an $\varepsilon$ value of 0 for summer and winter,

${ }_{527}$ respectively. When the surface is considered to be a perfect black body, which

528 is somewhat accurate when examining purely vegetated surfaces, the rural and

${ }_{529}$ urban reference temperatures are $30.26{ }^{\circ} \mathrm{C}$ and $32.29{ }^{\circ} \mathrm{C}$ during summer $(4.78$

$530{ }^{\circ} \mathrm{C}$ and $4.93{ }^{\circ} \mathrm{C}$ during winter), respectively. Note that the Stefan-Boltzmann

531 law is also an approximation, with slight uncertainties associated with the Ste-

532 fan-Boltzmann constant, deviations from the law seen for high and low tempera-

533 ture regimes, and the assumption of a black body (and by definition, lambertian

${ }_{534}$ surfaces) in the derivation of the equation (Baltes, 1973). 
b

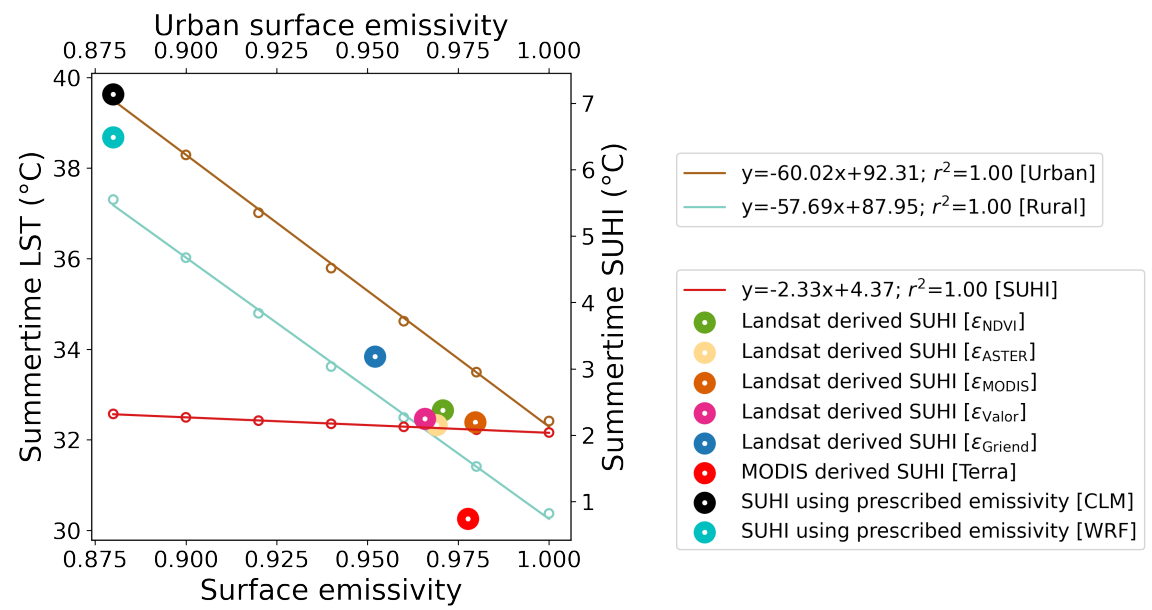

b

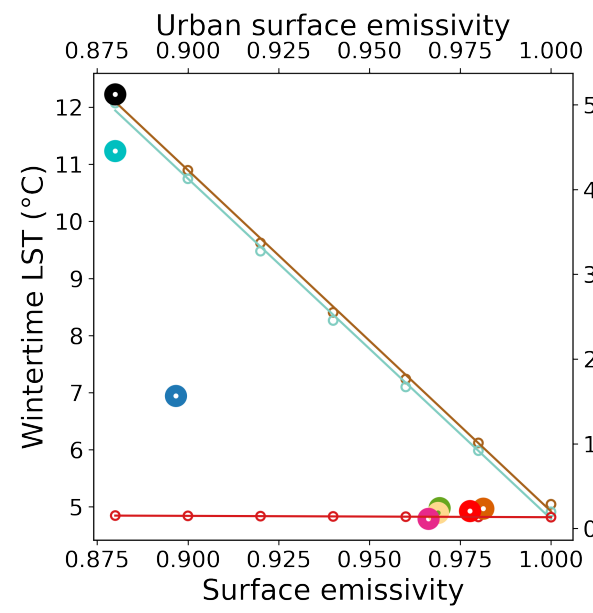

$\mathrm{y}=-59.75 \mathrm{x}+64.68 ; r^{2}=1.00$ [Urban]

$\mathrm{y}=-59.60 \mathrm{x}+64.38 ; r^{2}=1.00$ [Rural]

- $\mathrm{y}=-0.16 \mathrm{x}+0.29 ; r^{2}=1.00[\mathrm{SUHI}]$

- Landsat derived SUHI $\left[\varepsilon_{\mathrm{NDV} I}\right]$

(2) Landsat derived SUHI $\left[\varepsilon_{\mathrm{ASTER}}\right]$

- Landsat derived SUHI [ $\varepsilon_{\text {MODIS }}$ ]

- Landsat derived SUHI [ $\left.\varepsilon_{\text {Valor }}\right]$

- Landsat derived SUHI [ $\left.\varepsilon_{\text {Griend }}\right]$

- MODIS derived SUHI [Terra]

- SUHI using prescribed emissivity [CLM]

- SUHI using prescribed emissivity [WRF]

Figure 8: Sensitivity of urban and rural land surface temperature (LST), as well as surface urban heat island intensity (SUHI), to surface emissivity $(\varepsilon)$ assumptions for (a) summer and (b) winter days. The temperature sensitivity and SUHI sensitivities correspond to the left and right y-axes, respectively. The global mean values for different assumptions of $\varepsilon$ considered in this study and the prescribed $\varepsilon$ in the Weather Research and Forecasting (WRF) model and Community Land Model (CLM) are provided. The estimates are placed along the top $\mathrm{x}$ axis at the corresponding values for urban $\varepsilon$, since rural $\varepsilon$ varies little among these estimates.

The SUHI also decreases with increasing $\varepsilon$, with a summer bound of $2.04{ }^{\circ} \mathrm{C}$ and a wintertime value of $0.13{ }^{\circ} \mathrm{C}$ under the black body assumption for both 
urban and rural surfaces. We also show the impact of the prescribed urban and rural $\varepsilon$ using different methods on the global SUHI values. As discussed earlier, the lower $\varepsilon$ of urban areas compared to their rural references contributes to the SUHI. Among the $\varepsilon$ models tested, this difference is strongest for $\varepsilon_{\text {Griend }}$ (Eq. 7), with a summer mean SUHI of $3.18{ }^{\circ} \mathrm{C}$ using this method $\left(1.56{ }^{\circ} \mathrm{C}\right.$ during winter). The other methods, even with some differences in $\varepsilon_{\text {urb }}$, cluster close together when comes to the SUHI intensity. We also plot the global mean SUHI estimates from MODIS Terra observations, also discussed earlier. Of note, the difference in $\varepsilon_{\text {urb }}$ between Landsat and MODIS (global mean average of $\varepsilon_{\text {urb }}$ in band 31 and $32=\approx 0.978$ for both summer and winter) are minimal and would not explain the higher SUHI values from Landsat. We also show the impact of the prescribed urban and rural $\varepsilon$ values on simulated SUHI from two commonly used model, the Weather Research and Forecasting (WRF) Model (Powers et al., 2017) and the Community Land Model (CLM) (Lawrence et al. 2019). Although there are many models available for simulating urban climate with different assumptions and parameterizations, a complete survey of the $\varepsilon$ assumption in these models is beyond the scope of the current study. Instead, we provide an illustrative example from two important cases - with WRF being the mesoscale model used in the majority of urban climate research in the last decade (Kwok and Ng, 2021) and CLM being one of the few operational global climate models with explicit urban representation (Oleson and Feddema, 2020).

For WRF, we use the prescribed $\varepsilon$ for urban land (0.88) and forests $(0.95$ for coniferous, tropical, and sub-tropical forests) based on the model's land use lookup table (https://github.com/NCAR/WRFV3/blob/master/run/LANDUSE.TBL) to estimate the SUHI from the sensitivities shown in Fig. 8. For CLM, although $\varepsilon$ varies spatially, for simplicity, we use the values found for North America in Zhao et al. (2014), which is 0.88 for urban and 0.96 for rural. The theoretical SUHI calculated for the same urban clusters from models if the radiance differences between urban and rural areas were identical to that derived from the SMW algorithm is much higher than observed values (global mean of 6.48 and $7.13{ }^{\circ} \mathrm{C}$ for WRF and CLM, respectively, for summer; 4.45 and $5.12{ }^{\circ} \mathrm{C}$ 


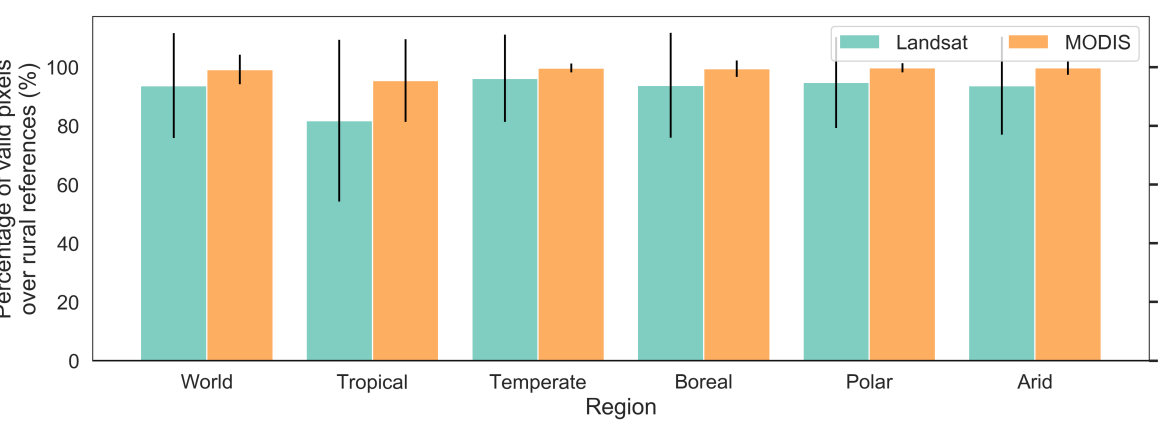

b

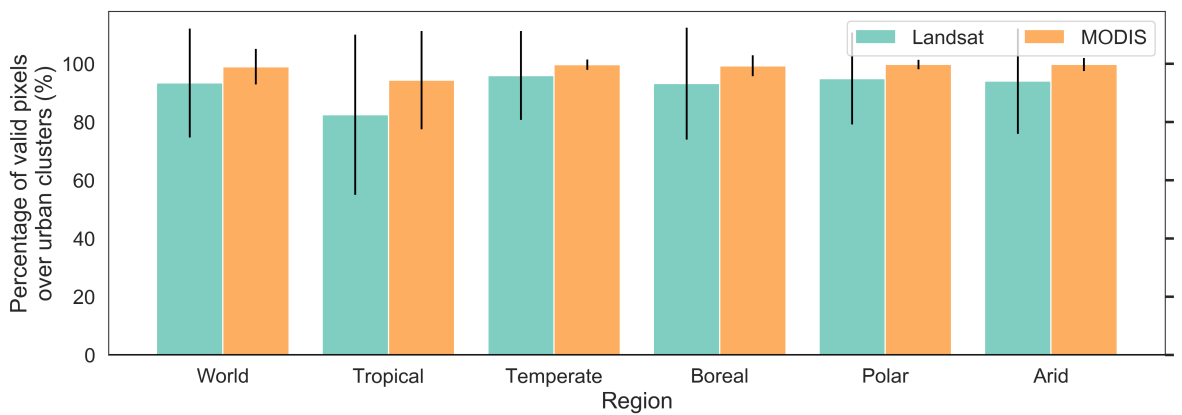

Figure 9: Mean and standard deviation of percentage of available pixels after temporal compositing during northern hemisphere summer from Landsat and MODIS data for all urban clusters (sub-figure (a) is for the rural references and (b) is for the urban references) and for each climate zone.

Unlike MODIS, which has been more frequently used for multi-city comparisons of SUHI, Landsat has a few advantages. The Landsat series has now 
Pickens et al., 2020). The Landsat TIR data are available since 1982, which provides an opportunity to study long-term trends in urban temperatures, which is not generally resolved using ground-based observational networks. Moreover, Landsat data being available at a higher resolution than MODIS allows us to more accurately detect thermal hotspots within urban areas. Unfortunately, the major limitation pertains to Landsat's 16-day return period. The probability of cloud contamination is much higher due to this lower frequency of measurements compared to daily MODIS scenes, particularly relevant for tropical and coastal areas. This is evident when we calculate the percentage of available pixels for the urban and rural references separately from Landsat and MODIS Terra measurements (Fig. 9). As expected, the percentage of available pixels for the urban references is higher for MODIS measurements (global composite mean of $99.0 \%$ for MODIS and $93.9 \%$ for Landsat). In tropical areas, the difference between the two products is further magnified with the composite mean of the available pixel percentage being $94.4 \%$ for MODIS and $81.9 \%$ for Landsat. The percentage of available pixels is similar for the rural references (Fig. $9 \mathrm{~b}$ ). Note that the available pixels are calculated here after temporal compositing i.e. at least one pixel is available during the northern hemisphere summer. In reality, Landsat would have a lower number of observations to estimate the pixel-level means, making it hard to compare these observations with more representative clear-sky estimates from MODIS. This lower frequency of measurements matters less for land cover classification since the timescale of land cover changes is usually larger than this return period. However, for dynamic variables like temperature, higher temporal resolution enables us to better constrain clear-sky climatological means, where Landsat would have issues, especially with potential inter-annual variability in cloud cover. To reduce the impact of this noise, we can consider multi-year compositing to define different regimes of SUHI corresponding to each past decade. Although this does reduce the number of data points available to calculate stable long-term trends, this issue will become less important with increasing years of LST data archival. With that being said, satellite observations from Landsat and MODIS do agree on overall regional 
patterns in SUHI and can continue to help monitor and provide insights on thermal anomalies associated with urbanization. However, the LST differences between datasets can be of the same order of magnitude as the SUHI signal (see Figs 4 and 7). Previous research has shown that choosing different MODISderived products (for instance, MYD11, which uses a split-window algorithm versus MYD21, which uses the ASTER TES algorithm) can lead to differences in SUHI estimates (Yao et al. 2020). The issue is more prevalent for Landsat, which currently lacks a globally available derived product (Yu et al. 2014 , Wang et al. 2019). A way forward may be to incorporate ensemble methods, as attempted here, to derive uncertainty ranges from multiple datasets and algorithms, thus accounting for differences in sensors, methods, surface emissivity, etc. This is important to consider in future work with more approaches to prescribing $\varepsilon$ and various retrieval algorithms. Doing so can improve our confidence in satellite-based SUHI estimates as we prepare for a warmer and more urbanized future.

Our comparison of the satellite-derived $\varepsilon$ with those prescribed in models comes with one major caveat. Since models use broadband $\varepsilon$ for longwave radiation, it might be misleading to compare the SUHI calculated using such broadband $\varepsilon$ values with the sensitivities found for channel-specific data. To examine further, we calculate broadband emissivities for each urban cluster from the ASTER data using the linear formulation described in Malakar et al. (2018):

$$
\varepsilon_{\mathrm{BB}}=c_{10} \varepsilon_{10}+c_{11} \varepsilon_{11}+c_{12} \varepsilon_{12}+c_{13} \varepsilon_{13}+c_{14} \varepsilon_{14}+c_{0}
$$

where $\varepsilon_{\mathrm{BB}}$ is the broadband emissivity, $\varepsilon_{10}, \varepsilon_{11}, \varepsilon_{12}, \varepsilon_{13}$, and $\varepsilon_{14}$ are the $\varepsilon$ values corresponding to channels 10 to 14 of the ASTER GEDv3 dataset, and $c_{10}$ $(=0.014), c_{11}(=0.145), c_{12}(=0.241), c_{13}(=0.467), c_{14}(=0.004)$ and $c_{0}(=0.128)$ are empirical coefficients. The distributions of $\varepsilon_{\mathrm{BB}}$ for urban and rural references, both globally and across climate classes, are shown in Figs 10a and 10b. Overall, urban $\varepsilon_{\mathrm{BB}}$ is slightly lower than rural $\varepsilon_{\mathrm{BB}}$. For rural references, arid 
regions tend to have the lowest $\varepsilon_{\mathrm{BB}}$ and boreal regions have the highest. It is evident that the ASTER-derived $\varepsilon_{\mathrm{BB}}$ for urban surfaces is higher than the 0.88 considered in CLM or WRF. Since this 0.88 in CLM is a bulk estimate of prescribed $\varepsilon$ for different urban components, we extracted the grid-level $\varepsilon$ in the surface dataset used in the latest version of CLM (CLM 5) and show their distributions using box and whisker plots (Fig. 10 ). The mean urban $\varepsilon_{\mathrm{BB}}$ calculated from ASTER GEDv3 (0.969) is also shown using the horizontal line. In almost all grids, the $\varepsilon$ values of the urban sub-components (across all urban classes) are lower than the ASTER estimates. Pervious surfaces in urban areas are prescribed to have an $\varepsilon$ of 0.95 . For other sub-components, CLM divides the world into 33 regions with their specific urban parameters, including $\varepsilon$ (Oleson and Feddema, 2020). The values of the $\varepsilon$ of roofs in CLM is particularly low. Unlike CLM, WRF generally uses a single land coverbased specification of $\varepsilon$ for urban areas. Figure 8 shows the potential SUHI value for WRF when run with the slab urban model, which assumes an urban $\varepsilon$ of 0.88 . In WRF with urban canyon representation, urban $\varepsilon$ is slightly higher and separated into $\varepsilon$ values for roofs (0.91), walls (0.91), and roads (0.95; https://github.com/NCAR/WRFV3/blob/master/run/URBPARM.TBL). Even if we assume that half of all urban areas are roads, the SUHI calculated using these prescribed emissivities would be higher than Landsat-derived values (global summer daytime mean of $3.35{ }^{\circ} \mathrm{C}$ versus ensemble mean Landsat-derived SUHI of $2.42{ }^{\circ} \mathrm{C}$ ). Since these $\varepsilon$ are not spatially explicit, some studies using WRF use the $\varepsilon$ specification from CLM (Huang et al. 2021). These sensitivity analyses (Fig. 8) also assume that the simulated outgoing longwave from the land components of the models would be identical to the values estimated from satellite observations. In reality, simulated LST is a function of not just $\varepsilon$, but is strongly modulated by other components of the surface energy balance. For CLM, decreases in prescribed $\varepsilon$ have been shown to increase the net radiation and sensible heat flux over urban surfaces (Oleson et al., 2008). Given the importance of $\varepsilon$ on constraining the surface energy budget and the somewhat larger variability in $\varepsilon$ expected in urban areas, future research should compare the 
${ }_{667}$ prescribed urban $\varepsilon$ and its impacts on simulated urban climate across currently 668 operational microscale, mesoscale, and global models. 


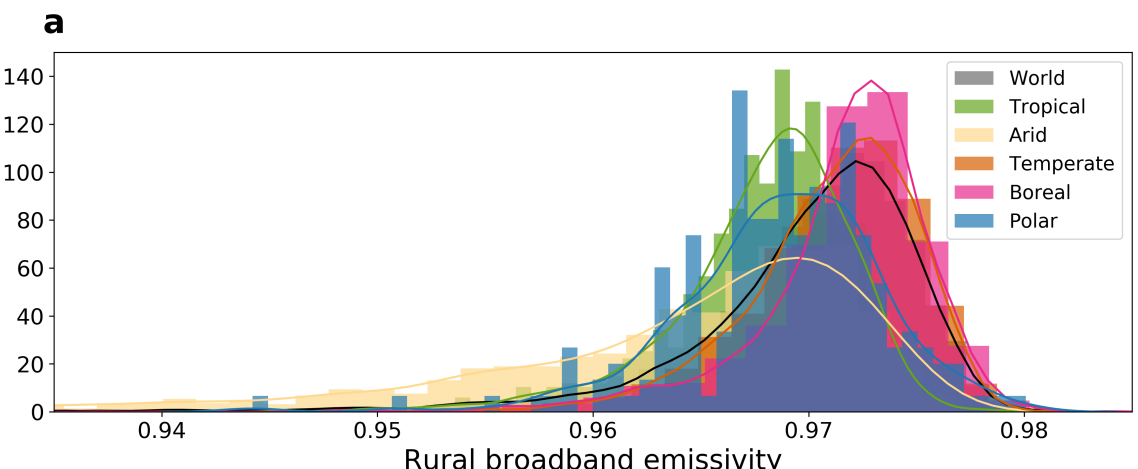

\section{b}

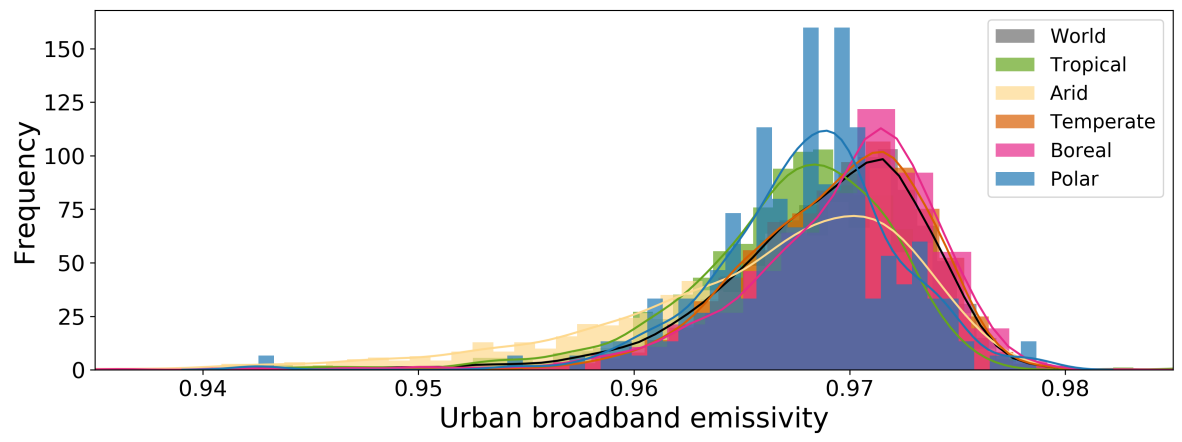

$$
\text { c }
$$

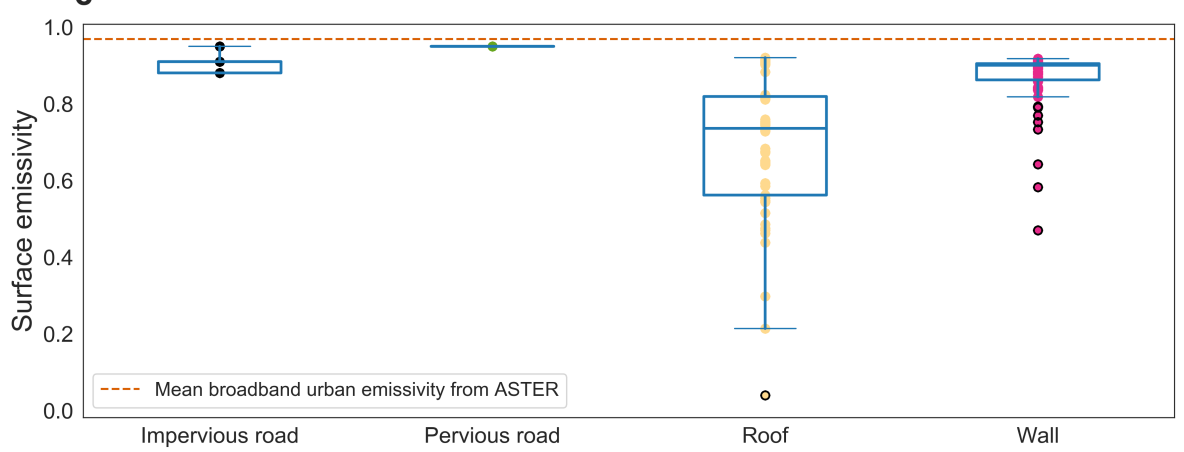

Figure 10: Sub-figures (a) and (b) show the frequency distribution histograms of rural and urban broadband emissivity $(\varepsilon)$ derived from ASTER data corresponding to all urban clusters and separately for each climate zone. Sub-figure (c) shows box and whisker plots of the prescribed broadband $\varepsilon$ of all urban sub-components throughout the globe in the latest version of the Community Land Model. The global mean urban broadband $\varepsilon$ from ASTER is also noted using the horizontal dashed line. 


\section{Limitations}

Our study focuses on a single year (2010) of Landsat 5 scenes. This is both to reduce computational time and also due to temporal constraints of the ancillary datasets (Esch et al., 2017, Hulley et al., 2015) used to compute the SUHI and its sensitivity to $\varepsilon$. Similar analysis for more recent years can be done using high resolution land cover datasets, such as GlobeLand30 (Chen et al., 2015) and GAIA (global artificial impervious area) (Gong et al., 2020), to delineate urban and rural pixels more accurately for the corresponding years. Landsat 5, although an older and currently nonoperational satellite, has the longest duration (1984-2013) of any Earth-observing satellite in history. As such, it has been critical for multiple long-term land cover and land use monitoring efforts (Liu et al., 2018, Pickens et al., 2020) and for temporal analysis of SUHI intensity (Shen et al., 2016). Moreover, the algorithms and $\varepsilon$ models considered here are also regularly used for Landsat 7 and 8 scenes with slight adjustments to empirical coefficients (Ermida et al., 2020, Sekertekin and Bonafoni, 2020a b). Thus, any insights about the importance of prescribed $\varepsilon$ on satellite-derived SUHI would be largely valid for all Landsat missions.

We confirm the generalizability of these results by calculating the corresponding variables (Fig. 11) for the 1000 largest urban clusters (after removing clusters with missing data for the relevant periods) for 2015 using Landsat 8 scenes. For this year, we use the World Settlement Footprint (Marconcini et al. 2020), a global map of human settlements available at $\approx 10 \mathrm{~m}$ resolution to dilineate urban and rural pixels within each cluster. The results, including the order of $\varepsilon$ values using the different approaches and the SUHI intensities across climate zones and seasons, are largely comparable to those found for Landsat 5 data for 2010 (Fig. 4). For instance, the summer (winter) daytime SUHI is 2.26 ${ }^{\circ} \mathrm{C}\left(0.39{ }^{\circ} \mathrm{C}\right)$ for 2010 using Landsat 5 versus $1.98{ }^{\circ} \mathrm{C}\left(0.26{ }^{\circ} \mathrm{C}\right)$ in 2015 using Landsat 8 for this subset of clusters.

In the present study, we only use one single-channel algorithm, the SMW algorithm, to compute LST. This is largely by design since the objective was 

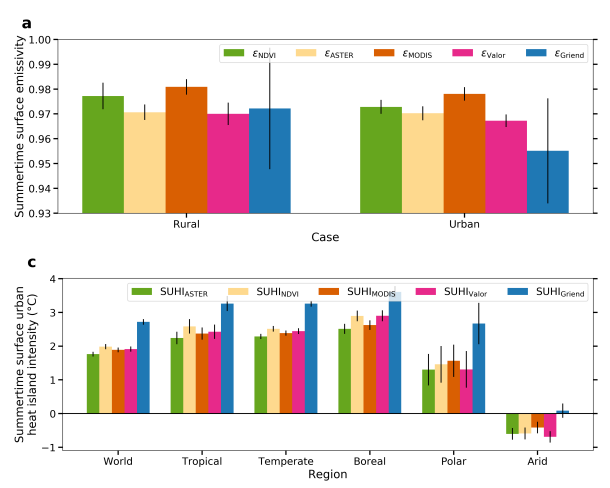

to employ this perturbation analysis to examine the impact of prescribed $\varepsilon$ on global and regional estimates of SUHI. We expect other algorithms to also be sensitive to $\varepsilon$ models but to different degrees (Sekertekin and Bonafoni, 2020a b).
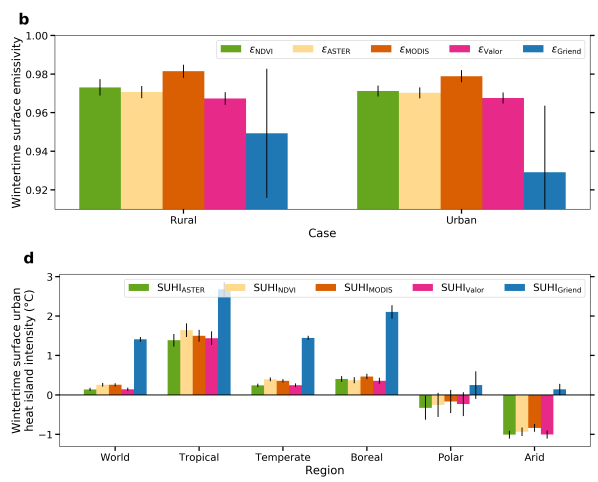

Figure 11: Sub-figures (a) and (b) show the mean and standard deviation of urban and rural surface emissivity $(\varepsilon)$ for summer and winter, respectively, from all the approaches considered in the present study for the 1000 largest urban clusters (991 for summer and 849 for winter after quality screening) for the year 2015 using Landsat 8 measurements. Sub-figures (c) and (d) show the mean and standard error of surface urban heat island intensity for summer and winter, respectively, for the corresponding clusters as well as for each climate zone using the different methods of prescribing $\varepsilon$.

It should be stressed that the empirical relationships used to estimate LST from TIR data, as well as the methods used to estimate $\varepsilon$, were originally designed for natural surfaces, not urban areas (Van de Griend and OWE, 1993 Sekertekin and Bonafoni, 2020a). More importantly, ground-based validation of $\varepsilon$ is still rare (Langsdale et al., 2020), and particularly difficult for urban areas due to their heterogeneity. For instance, none of the SURFRAD stations Augustine et al. 2005), commonly used to evaluate satellite-derived LST (Ermida et al., 2020 Sekertekin and Bonafoni, 2020a b) are in cities. Without such validations, we can expect uncertainties in urban LST and thus, larger noise-to-signal ratios for satellite-derived SUHI. Since Landsat observations allow us to estimate intra-urban variability in SUHI at a higher resolution, an important question is how this $\varepsilon$ is affected by the change in surface roughness 
within urban areas and how that impacts our estimates of spatial LST variability. This surface heterogeneity will affect both bulk $\varepsilon$ estimates and lead to thermal anisotropy, which can further amplify the deviations between MODIS and Landsat LST given their different view angles ( $\mathrm{Hu}$ et al., 2016, Krayenhoff and Voogt, 2016, Wang et al., 2021).

Finally, when comparing modeled SUHI with satellite observations, it is important to consider the fundamental differences between them. Prescribed $\varepsilon$ in models are from material-level $\varepsilon$ for broadband thermal radiation, which can be quite low Artis and Carnahan, 1982). However, most real urban surfaces are not just slabs of constant built-up materials. This introduces difficulties in performing apples-to-apples comparisons between large-scale estimates from satellites and models, since they do not necessarily agree on a common definition for urban areas.

\section{Conclusion}

Approaches used to prescribe land emissivity in surface temperature retrieval algorithms can have a strong impact on surface urban heat island (SUHI) estimates, particularly for more vegetated regions. In the present study, we test five such approaches across almost 10,000 urban clusters using Landsat 5 data and the statistical mono-window algorithm for the year 2010. Adjusting the surface emissivity using satellite-derived proxies of vegetation increases the contrast between summer and wintertime SUHI. We provide the first estimates of SUHI at a global scale using Landsat data by combining all these approaches. Landsat-derived SUHI is generally higher than MODIS-derived values, though they show similar seasonal and climatic trends. More interestingly, we find that the prescribed urban emissivity in common weather and climate models may be biased low, which would impact the model-simulated SUHI values. Our results show a need to comprehensively benchmark urban emissivity values used in both satellite remote sensing and numerical weather and climate modeling. Further research is also needed to examine how sensitive these emissivity assumptions 
743 are for other surface temperature retrieval algorithms. With the continued and unprecedented urbanization and given that the approaches to derive surface emissivity were initially intended for natural land cover, we need to take a step 746 back to evaluate these methods specifically over urban areas or develop new 747 algorithms to reduce uncertainties when studying urban climate. 


\section{References}

Abrams, M., 2000. The advanced spaceborne thermal emission and reflection radiometer (aster): data products for the high spatial resolution imager on nasa's terra platform. international Journal of Remote sensing 21, 847-859.

Arnfield, A.J., 2003. Two decades of urban climate research: a review of turbulence, exchanges of energy and water, and the urban heat island. International journal of climatology 23, 1-26. Publisher: Wiley Online Library.

Artis, D.A., Carnahan, W.H., 1982. Survey of emissivity variability in thermography of urban areas. Remote sensing of Environment 12, 313-329.

Augustine, J.A., Hodges, G.B., Cornwall, C.R., Michalsky, J.J., Medina, C.I., 2005. An update on surfrad - the gcos surface radiation budget network for the continental united states. Journal of Atmospheric and Oceanic Technology $22,1460-1472$.

Baltes, H., 1973. Deviations from the stefan boltzmann law at low temperatures. Applied physics 1, 39-43.

Bonafoni, S., Anniballe, R., Gioli, B., Toscano, P., 2016. Downscaling landsat land surface temperature over the urban area of florence. European Journal of Remote Sensing 49, 553-569.

Bonafoni, S., Anniballe, R., Pichierri, M., 2015. Comparison between surface and canopy layer urban heat island using MODIS data, in: 2015 Joint Urban Remote Sensing Event (JURSE), IEEE. pp. 1-4.

Carlson, T.N., Arthur, S.T., 2000. The impact of land use-land cover changes due to urbanization on surface microclimate and hydrology: a satellite perspective. Global and planetary change 25, 49-65.

Carlson, T.N., Ripley, D.A., 1997. On the relation between ndvi, fractional vegetation cover, and leaf area index. Remote sensing of Environment 62, 241-252. 
Chakraborty, T., Hsu, A., Manya, D., Sheriff, G., 2019a. Disproportionately higher exposure to urban heat in lower-income neighborhoods: a multi-city perspective. Environmental Research Letters 14, 105003. URL: https:// iopscience.iop.org/article/10.1088/1748-9326/ab3b99, doi10.1088/ 1748-9326/ab3b99

Chakraborty, T., Hsu, A., Manya, D., Sheriff, G., 2020. A spatially explicit surface urban heat island database for the united states: Characterization, uncertainties, and possible applications. ISPRS Journal of Photogrammetry and Remote Sensing 168, 74-88.

Chakraborty, T., Lee, X., 2019. A simplified urban-extent algorithm to characterize surface urban heat islands on a global scale and examine vegetation control on their spatiotemporal variability. International Journal of Applied Earth Observation and Geoinformation 74, 269-280. URL: https: //linkinghub.elsevier.com/retrieve/pii/S0303243418304653, doi 10 . $1016 / \mathrm{j} \cdot \mathrm{jag} .2018 .09 .015$.

Chakraborty, T., Sarangi, C., Krishnan, M., Tripathi, S.N., Morrison, R., Evans, J., 2019b. Biases in model-simulated surface energy fluxes during the indian monsoon onset period. Boundary-Layer Meteorology 170, 323-348.

Chakraborty, T., Sarangi, C., Tripathi, S.N., 2016. Understanding diurnality and inter-seasonality of a sub-tropical urban heat-island. Boundary-Layer Meteorology Publisher: Springer.

Chen, F., Yang, S., Su, Z., Wang, K., 2016. Effect of emissivity uncertainty on surface temperature retrieval over urban areas: Investigations based on spectral libraries. ISPRS journal of photogrammetry and remote sensing 114, $53-65$.

Chen, J., Chen, J., Liao, A., Cao, X., Chen, L., Chen, X., He, C., Han, G., Peng, S., Lu, M., et al., 2015. Global land cover mapping at $30 \mathrm{~m}$ resolution: A pok-based operational approach. ISPRS Journal of Photogrammetry and Remote Sensing 103, 7-27. 
Clinton, N., Gong, P., 2013. Modis detected surface urban heat islands and sinks: Global locations and controls. Remote Sensing of Environment 134, 294-304.

Danielson, J.J., Gesch, D.B., 2011. Global multi-resolution terrain elevation data 2010 (GMTED2010). US Department of the Interior, US Geological Survey.

Dash, P., Göttsche, F.M., Olesen, F.S., Fischer, H., 2002. Land surface temperature and emissivity estimation from passive sensor data: Theory and practice-current trends. International Journal of remote sensing 23, 25632594.

Duguay-Tetzlaff, A., Bento, V.A., Göttsche, F.M., Stöckli, R., Martins, J., Trigo, I., Olesen, F., Bojanowski, J.S., Da Camara, C., Kunz, H., 2015. Meteosat land surface temperature climate data record: Achievable accuracy and potential uncertainties. Remote Sensing 7, 13139-13156.

Ermida, S.L., Soares, P., Mantas, V., Göttsche, F.M., Trigo, I.F., 2020. Google earth engine open-source code for land surface temperature estimation from the landsat series. Remote Sensing 12, 1471.

Esch, T., Heldens, W., Hirner, A., Keil, M., Marconcini, M., Roth, A., Zeidler, J., Dech, S., Strano, E., 2017. Breaking new ground in mapping human settlements from space-the global urban footprint. ISPRS Journal of Photogrammetry and Remote Sensing 134, 30-42.

Gillespie, A., Rokugawa, S., Matsunaga, T., Cothern, J.S., Hook, S., Kahle, A.B., 1998. A temperature and emissivity separation algorithm for advanced spaceborne thermal emission and reflection radiometer (aster) images. IEEE transactions on geoscience and remote sensing 36, 1113-1126.

Gong, P., Li, X., Wang, J., Bai, Y., Chen, B., Hu, T., Liu, X., Xu, B., Yang, J., Zhang, W., et al., 2020. Annual maps of global artificial impervious area (gaia) between 1985 and 2018. Remote Sensing of Environment 236, 111510. 
Gorelick, N., Hancher, M., Dixon, M., Ilyushchenko, S., Thau, D., Moore, R., 2017. Google earth engine: Planetary-scale geospatial analysis for everyone. Remote sensing of Environment 202, 18-27.

Van de Griend, A., OWE, M., 1993. On the relationship between thermal emissivity and the normalized difference vegetation index for natural surfaces. International Journal of remote sensing 14, 1119-1131.

Hoffman, J.S., Shandas, V., Pendleton, N., 2020. The effects of historical housing policies on resident exposure to intra-urban heat: a study of 108 us urban areas. Climate 8, 12.

Hook, S.J., Gabell, A.R., Green, A.A., Kealy, P.S., 1992. A comparison of techniques for extracting emissivity information from thermal infrared data for geologic studies. Remote Sensing of Environment 42, 123-135.

Hsu, A., Sheriff, G., Chakraborty, T., Manya, D., 2021. Disproportionate exposure to urban heat island intensity across major us cities. Nature communications $12,1-11$.

Hu, L., Brunsell, N.A., 2013. The impact of temporal aggregation of land surface temperature data for surface urban heat island (SUHI) monitoring. Remote Sensing of Environment 134, 162-174. Publisher: Elsevier.

Hu, L., Monaghan, A., Voogt, J.A., Barlage, M., 2016. A first satellite-based observational assessment of urban thermal anisotropy. Remote sensing of environment 181, 111-121.

Huang, K., Lee, X., Stone Jr, B., Knievel, J., Bell, M.L., Seto, K.C., 2021. Persistent increases in nighttime heat stress from urban expansion despite heat island mitigation. Journal of Geophysical Research: Atmospheres , e2020JD033831.

Hulley, G.C., Hook, S.J., Abbott, E., Malakar, N., Islam, T., Abrams, M., 2015. The aster global emissivity dataset (aster ged): Mapping earth's emissivity at 100 meter spatial scale. Geophysical Research Letters 42, 7966-7976. 
Jiménez-Muñoz, J.C., Sobrino, J.A., 2003. A generalized single-channel method for retrieving land surface temperature from remote sensing data. Journal of geophysical research: atmospheres 108.

Jin, M., Liang, S., 2006. An improved land surface emissivity parameter for land surface models using global remote sensing observations. Journal of Climate $19,2867-2881$.

Krayenhoff, E.S., Voogt, J.A., 2016. Daytime thermal anisotropy of urban neighbourhoods: Morphological causation. Remote Sensing 8, 108.

Kumar, R., Mishra, V., Buzan, J., Kumar, R., Shindell, D., Huber, M., 2017. Dominant control of agriculture and irrigation on urban heat island in india. Scientific reports 7, 1-10.

Kwok, Y.T., Ng, E.Y.Y., 2021. Trends, topics, and lessons learnt from real case studies using mesoscale atmospheric models for urban climate applications in 2000-2019. Urban Climate 36, 100785.

Lagouarde, J.P., Moreau, P., Irvine, M., Bonnefond, J.M., Voogt, J.A., Solliec, F., 2004. Airborne experimental measurements of the angular variations in surface temperature over urban areas: case study of marseille (france). Remote Sensing of Environment 93, 443-462.

Langsdale, M.F., Dowling, T.P., Wooster, M., Johnson, J., Grosvenor, M.J., de Jong, M.C., Johnson, W.R., Hook, S.J., Rivera, G., 2020. Inter-comparison of field-and laboratory-derived surface emissivities of natural and manmade materials in support of land surface temperature (lst) remote sensing. Remote Sensing 12, 4127.

Lawrence, D.M., Fisher, R.A., Koven, C.D., Oleson, K.W., Swenson, S.C., Bonan, G., Collier, N., Ghimire, B., van Kampenhout, L., Kennedy, D., et al., 2019. The community land model version 5: Description of new features, benchmarking, and impact of forcing uncertainty. Journal of Advances in Modeling Earth Systems 11, 4245-4287. 
Li, H., Meier, F., Lee, X., Chakraborty, T., Liu, J., Schaap, M., Sodoudi, S., 2018. Interaction between urban heat island and urban pollution island during summer in berlin. Science of the total environment 636, 818-828.

Li, M., Wang, T., Xie, M., Zhuang, B., Li, S., Han, Y., Song, Y., Cheng, N., 2017. Improved meteorology and ozone air quality simulations using modis land surface parameters in the yangtze river delta urban cluster, china. Journal of Geophysical Research: Atmospheres 122, 3116-3140.

Li, X., Zhou, Y., Yu, S., Jia, G., Li, H., Li, W., 2019. Urban heat island impacts on building energy consumption: A review of approaches and findings. Energy $174,407-419$.

Li, Z.L., Tang, B.H., Wu, H., Ren, H., Yan, G., Wan, Z., Trigo, I.F., Sobrino, J.A., 2013a. Satellite-derived land surface temperature: Current status and perspectives. Remote sensing of environment 131, 14-37.

Li, Z.L., Wu, H., Wang, N., Qiu, S., Sobrino, J.A., Wan, Z., Tang, B.H., Yan, G., 2013b. Land surface emissivity retrieval from satellite data. International Journal of Remote Sensing 34, 3084-3127.

Liu, X., Hu, G., Chen, Y., Li, X., Xu, X., Li, S., Pei, F., Wang, S., 2018. Highresolution multi-temporal mapping of global urban land using landsat images based on the google earth engine platform. Remote sensing of environment 209, 227-239.

Loveland, T.R., Dwyer, J.L., 2012. Landsat: Building a strong future. Remote Sensing of Environment 122, 22-29.

Malakar, N.K., Hulley, G.C., Hook, S.J., Laraby, K., Cook, M., Schott, J.R., 2018. An operational land surface temperature product for landsat thermal data: Methodology and validation. IEEE Transactions on Geoscience and Remote Sensing 56, 5717-5735.

Manoli, G., Fatichi, S., Bou-Zeid, E., Katul, G.G., 2020. Seasonal hysteresis of surface urban heat islands. Proceedings of 


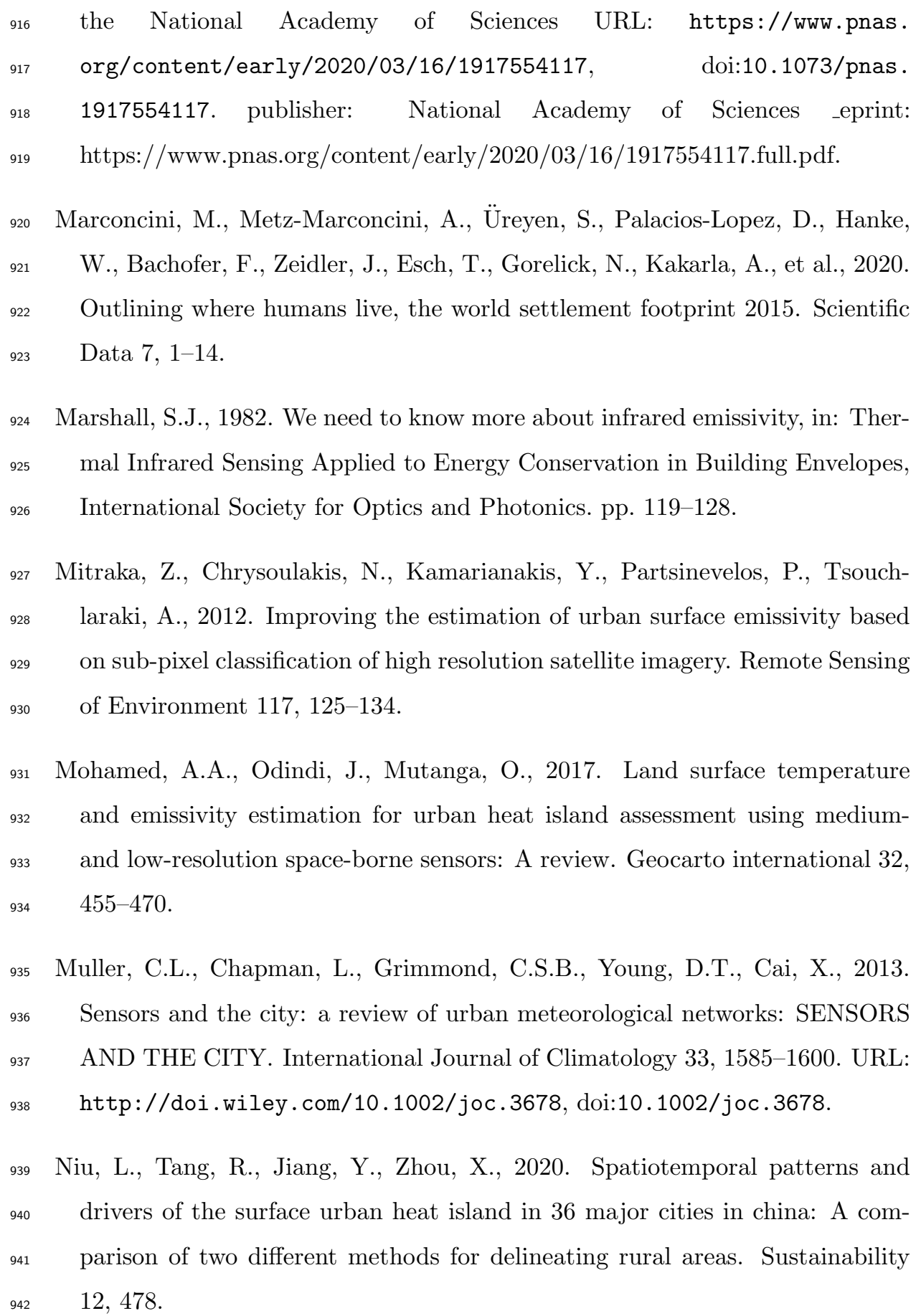


Oke, T., 1969. Towards a more rational understanding of the urban heat island. McGill Climatol Bull 5, 1-21.

Oke, T.R., 1982. The energetic basis of the urban heat island. Quarterly Journal of the Royal Meteorological Society 108, 1-24. Publisher: Wiley Online Library.

Oleson, K., Feddema, J., 2020. Parameterization and surface data improvements and new capabilities for the community land model urban (clmu). Journal of advances in modeling earth systems 12, e2018MS001586.

Oleson, K.W., Bonan, G.B., Feddema, J., Vertenstein, M., 2008. An urban parameterization for a global climate model. part ii: Sensitivity to input parameters and the simulated urban heat island in offline simulations. Journal of Applied Meteorology and Climatology 47, 1061-1076.

Pekel, J.F., Cottam, A., Gorelick, N., Belward, A.S., 2016. High-resolution mapping of global surface water and its long-term changes. Nature 540, 418422.

Peng, S., Piao, S., Ciais, P., Friedlingstein, P., Ottle, C., Bréon, F.M., Nan, H., Zhou, L., Myneni, R.B., 2011. Surface urban heat island across 419 global big cities. Environmental science \& technology 46, 696-703. Publisher: ACS Publications.

Peres, L.F., DaCamara, C.C., 2005. Emissivity maps to retrieve land-surface temperature from msg/seviri. IEEE Transactions on Geoscience and Remote Sensing 43, 1834-1844.

Pickens, A.H., Hansen, M.C., Hancher, M., Stehman, S.V., Tyukavina, A., Potapov, P., Marroquin, B., Sherani, Z., 2020. Mapping and sampling to characterize global inland water dynamics from 1999 to 2018 with full landsat time-series. Remote Sensing of Environment 243, 111792.

Powers, J.G., Klemp, J.B., Skamarock, W.C., Davis, C.A., Dudhia, J., Gill, D.O., Coen, J.L., Gochis, D.J., Ahmadov, R., Peckham, S.E., et al., 2017. 
The weather research and forecasting model: Overview, system efforts, and future directions. Bulletin of the American Meteorological Society 98, 17171737.

Quan, J., Zhan, W., Chen, Y., Wang, M., Wang, J., 2016. Time series decomposition of remotely sensed land surface temperature and investigation of trends and seasonal variations in surface urban heat islands. Journal of Geophysical Research: Atmospheres 121, 2638-2657.

Rao, P.K., 1972. Remote sensing of urban" heat islands" from an environmental satellite. Bulletin of the American meteorological society 53, 647-648.

Ren, H., Liu, R., Qin, Q., Fan, W., Yu, L., Du, C., 2017. Mapping finerresolution land surface emissivity using landsat images in china. Journal of Geophysical Research: Atmospheres 122, 6764-6781.

Rubel, F., Kottek, M., 2010. Observed and projected climate shifts 1901-2100 depicted by world maps of the köppen-geiger climate classification. Meteorologische Zeitschrift 19, 135.

Schneider, A., Friedl, M.A., Potere, D., 2010. Mapping global urban areas using modis 500-m data: New methods and datasets based on 'urban ecoregions'. Remote Sensing of Environment 114, 1733-1746.

Sekertekin, A., Bonafoni, S., 2020a. Land surface temperature retrieval from landsat 5, 7, and 8 over rural areas: assessment of different retrieval algorithms and emissivity models and toolbox implementation. Remote Sensing 12, 294.

Sekertekin, A., Bonafoni, S., 2020b. Sensitivity analysis and validation of daytime and nighttime land surface temperature retrievals from landsat 8 using different algorithms and emissivity models. Remote Sensing 12, 2776.

Sellers, P., Mintz, Y., Sud, Y.e.a., Dalcher, A., 1986. A simple biosphere model (sib) for use within general circulation models. Journal of Atmospheric Sciences $43,505-531$. 
Shastri, H., Paul, S., Ghosh, S., Karmakar, S., 2015. Impacts of urbanization on Indian summer monsoon rainfall extremes. Journal of Geophysical Research: Atmospheres 120, 496-516. Publisher: Wiley Online Library.

Shen, H., Huang, L., Zhang, L., Wu, P., Zeng, C., 2016. Long-term and finescale satellite monitoring of the urban heat island effect by the fusion of multi-temporal and multi-sensor remote sensed data: A 26-year case study of the city of wuhan in china. Remote Sensing of Environment 172, 109-125.

Snyder, W.C., Wan, Z., Zhang, Y., Feng, Y.Z., 1998. Classification-based emissivity for land surface temperature measurement from space. International Journal of Remote Sensing 19, 2753-2774.

Sobrino, J.A., Oltra-Carrió, R., Jiménez-Muñoz, J.C., Julien, Y., Soria, G., Franch, B., Mattar, C., 2012. Emissivity mapping over urban areas using a classification-based approach: Application to the dual-use european security ir experiment (desirex). International Journal of Applied Earth Observation and Geoinformation 18, 141-147.

Stewart, I.D., 2011. A systematic review and scientific critique of methodology in modern urban heat island literature. International Journal of Climatology 31, 200-217. Publisher: Wiley Online Library.

Strahler, A., 1999. Modis land cover product algorithm theoretical basis document (atbd) version 5.0. http://modis. gsfc. nasa. gov/data/atbd/atbd_mod12. pdf .

Tang, R., Li, Z.L., Tang, B., 2010. An application of the ts-vi triangle method with enhanced edges determination for evapotranspiration estimation from modis data in arid and semi-arid regions: Implementation and validation. Remote Sensing of Environment 114, 540-551.

Theeuwes, N.E., Barlow, J.F., Teuling, A.J., Grimmond, C.S.B., Kotthaus, S., 2019. Persistent cloud cover over mega-cities linked to surface heat release. npj Climate and Atmospheric Science 2, 1-6. 
Turner, A.G., Bhat, G., Martin, G., Parker, D.J., Taylor, C., Mitra, A.K., Tripathi, S.N., Milton, S., Rajagopal, E., Evans, J.G., et al., 2020. Interaction of convective organization with monsoon precipitation, atmosphere, surface and sea: The 2016 incompass field campaign in india. Quarterly Journal of the Royal Meteorological Society 146, 2828-2852.

Valor, E., Caselles, V., 1996. Mapping land surface emissivity from ndvi: Application to european, african, and south american areas. Remote sensing of Environment 57, 167-184.

Venter, Z.S., Chakraborty, T., Lee, X., 2021. Crowdsourced air temperatures contrast satellite measures of the urban heat island and its mechanisms. Science Advances 7, eabb9569.

Voogt, J., 2007. How researchers measure urban heat islands, in: United States Environmental Protection Agency (EPA), State and Local Climate and Energy Program, Heat Island Effect, Urban Heat Island Webcasts and Conference Calls.

Voogt, J.A., Oke, T., 1998. Effects of urban surface geometry on remotely-sensed surface temperature. International Journal of Remote Sensing 19, 895-920.

Voogt, J.A., Oke, T.R., 2003. Thermal remote sensing of urban climates. Remote sensing of environment $86,370-384$.

Wan, Z., et al., 2006. Modis land surface temperature products users' guide. ICESS, University of California .

Wang, D., Chen, Y., Hu, L., Voogt, J.A., Gastellu-Etchegorry, J.P., Krayenhoff, E.S., 2021. Modeling the angular effect of modis lst in urban areas: A case study of toulouse, france. Remote Sensing of Environment 257, 112361.

Wang, F., Qin, Z., Song, C., Tu, L., Karnieli, A., Zhao, S., 2015. An improved mono-window algorithm for land surface temperature retrieval from landsat 8 thermal infrared sensor data. Remote sensing 7, 4268-4289. 
Wang, L., Lu, Y., Yao, Y., 2019. Comparison of three algorithms for the retrieval of land surface temperature from landsat 8 images. Sensors 19, 5049 .

Yang, J., Wong, M.S., Menenti, M., Nichol, J., 2015. Modeling the effective emissivity of the urban canopy using sky view factor. ISPRS Journal of Photogrammetry and Remote Sensing 105, 211-219.

Yang, Q., Huang, X., Tang, Q., 2019. The footprint of urban heat island effect in 302 chinese cities: Temporal trends and associated factors. Science of the Total Environment 655, 652-662.

Yao, R., Wang, L., Huang, X., Gong, W., Xia, X., 2019. Greening in rural areas increases the surface urban heat island intensity. Geophysical Research Letters 46, 2204-2212.

Yao, R., Wang, L., Wang, S., Wang, L., Wei, J., Li, J., Yu, D., 2020. A detailed comparison of myd11 and myd21 land surface temperature products in mainland china. International Journal of Digital Earth 13, 1391-1407.

Yu, X., Guo, X., Wu, Z., 2014. Land surface temperature retrieval from landsat 8 tirs - comparison between radiative transfer equation-based method, split window algorithm and single channel method. Remote sensing 6, 9829-9852.

Zhan, W., Chen, Y., Zhou, J., Wang, J., Liu, W., Voogt, J., Zhu, X., Quan, J., Li, J., 2013. Disaggregation of remotely sensed land surface temperature: Literature survey, taxonomy, issues, and caveats. Remote Sensing of Environment 131, 119-139.

Zhang, P., Imhoff, M.L., Wolfe, R.E., Bounoua, L., 2010. Characterizing urban heat islands of global settlements using modis and nighttime lights products. Canadian Journal of Remote Sensing 36, 185-196.

Zhang, Q., Zhang, M., Zhou, W., Xu, W., Zhang, J., 2019. The influence of different urban and rural selection methods on the spatial variation of urban heat island intensity, in: IGARSS 2019-2019 IEEE International Geoscience and Remote Sensing Symposium, IEEE. pp. 4403-4406. 
Zhao, L., Lee, X., Smith, R.B., Oleson, K., 2014. Strong contributions of local background climate to urban heat islands. Nature 511, 216-219. Publisher: Nature Publishing Group.

Zhisheng, A., Guoxiong, W., Jianping, L., Youbin, S., Yimin, L., Weijian, Z., Yanjun, C., Anmin, D., Li, L., Jiangyu, M., et al., 2015. Global monsoon dynamics and climate change. Annual Review of Earth and Planetary Sciences 43, 29-77.

Zhou, D., Zhao, S., Zhang, L., Sun, G., Liu, Y., 2015. The footprint of urban heat island effect in china. Scientific reports 5, 1-11. 